\title{
MGIDI and WAASB indices: The useful approaches for selection of salt-tolerant barley genotype at the early growth and maturity stages
}

Alireza Pour-Aboughadareh ( $\sim$ a.poraboghadareh@edu.ikiu.ac.ir)

Imam Khomeini International University https://orcid.org/0000-0001-5782-5327

\section{Sara Sanjani}

Seed and Plant Improvement Research Institute

Hamidreza Nikkhah Chaman-Abad

Khorasan Razavi Agricultural and Natural Resources Research

Mohammad Reza Mehrvar

Seed and Plant Improvement Research Institute

Ameneh Asadi

Seed and Plant Improvement Research Institute

Ashkboos Amini

Seed and Plant Improvement Research Institute

\section{Research Article}

Keywords: Salt stress, Multi-environment trials (METs), Genotype-by-environment interaction, MGIDI index, Physiological traits

Posted Date: March 8th, 2021

DOl: https://doi.org/10.21203/rs.3.rs-304576/v1

License: (c) (i) This work is licensed under a Creative Commons Attribution 4.0 International License.

Read Full License 
MGIDI and WAASB indices: The useful approaches for selection of salt-tolerant barley genotype at the early growth and maturity stages

Alireza Pour-Aboughadareh ${ }^{1 *}$, Sara Sanjani' ${ }^{1}$, Hamidreza Nikkhah Chaman-Abad ${ }^{2}$, Mohammad Reza Mehrvar', Ameneh Asadi ${ }^{1}$, Ashkboos Amini ${ }^{1}$

${ }^{1}$ Seed and Plant Improvement Institute, Agricultural Research, Education and Extension Organization (AREEO), Karaj 5782-5327, Iran

${ }^{2}$ Razavi Khorasan Agricultural and Natural Resources Research and Education Center, Agricultural Research, Education and Extension Organization (AREEO), Mashhad, Iran

\section{*Corresponding author:}

Alireza Pour-Aboughadareh

Emails: a.poraboghadareh@gmail.com or a.poraboghadareh@edu.ikiu.ac.ir or a.poraboghadareh@ut.ac.ir ORCID: 0000-0001-5782-5327

Tell: (+98) 9183830915

Fax: (+98) 2636702698 


\title{
MGIDI and WAASB indices: The useful approaches for selection of salt-tolerant barley genotype at
}

\section{the early growth and maturity stages}

\begin{abstract}
Salinity stress is one of the major limiting abiotic stresses that decrease crop production worldwide. To recommend genotypes for cultivation under saline stress conditions, comprehensive understanding of genetic basis and plant responses to this stress is need. In the present study, a total of 20 barley genotypes were investigated to isolate potential salt-tolerant genotypes at the early growth stage using hydroponic system, and adult plant under field conditions. Different growth and physiological traits including root fresh and dry weights (RFW and RDW), shoot fresh and dry weights (SFW and SDW), relative water content (RWC), membrane stability index (MSI), relative chlorophyll content (SPAD index), root and shoot $\mathrm{Na}^{+}(\mathrm{RN}$ and $\mathrm{SN})$, root and shoot $\mathrm{K}^{+}(\mathrm{RK}$ and $\mathrm{SK})$, root and shoot $\mathrm{K}^{+}: \mathrm{Na}^{+}$ratios $\left(\mathrm{RKN}^{\mathrm{N}}\right.$ and SKN), root-to-shoot $\mathrm{Na}^{+}$translocation (RTSN), root-to-shoot $\mathrm{K}^{+}$translocation (RTSK), stomatal conductance $\left(G_{S}\right)$, transpiration rate $\left(T_{E}\right)$, and photosynthesis rate $\left(P_{N}\right)$ were measured. Barley seedling were treated with two salinity levels ( $0 \mathrm{mM} \mathrm{NaCl}$ (as control conditions) and $200 \mathrm{mM} \mathrm{NaCl}$ (as stress conditions)) for 30 days. Moreover, the yield performance and stability of investigated barley genotypes were evaluated across five environments during the 2018-2020 cropping seasons. Salinity stress significantly decreased growth and physiological traits in all seedling plants; however, some salt-tolerant genotypes showed the lowest reduction in measured traits. Multivariate analysis grouped measured traits and tested genotypes into different clusters. The multi-trait genotype-ideotype distance index (MGIDI) selected genotypes G12, G14, G6, G7, and G16 as the salt-tolerant barley genotypes. Considering the results of the AMMI analysis showed that grain yields of tested barley genotypes were influenced by environment (E), genotype $(\mathrm{G})$ and GE interaction effects. Based on the weighted average of absolute scores of the genotype index $(W A A S B)$ and other stability statistics, G7, G8, G14, and G16 were selected as superior genotypes. Considering the outputs of MGIDI and WAASB indices revealed that three genotypes G7, G14 and G16 can be recommended as new genetic resources for improving and stabilizing grain yield in barley programs for the moderate climate and saline regions of Iran. In conclusion, our results suggest that the using MGIDI index in the early growth stage can accelerate screening nurseries in barley breeding programs.
\end{abstract}

Keywords: Salt stress, Multi-environment trials (METs), Genotype-by-environment interaction, MGIDI index, Physiological traits

\section{Introduction}

Among cereal crops, barley (Hordeum vulgare L.) is known as one of the main tolerant cereal to abiotic stresses in the world and Iran (Ahakpaz et al. 2021). These ranks are referred to this fact, this cereal is one of the most salineand drought-tolerant crop and is frequently used as a model to comprehend resistance mechanisms in plants (Mwando et al. 2020). Among environmental stresses, salinity is a major global factor limiting crop productivity and food security around the world (Rasel et al. 2020). It has been reported that more than 800 million hectares (Mha) of land worldwide are located in saline regions (Dasgupta et al. 2015). Nevertheless, increased soil salinization in many croplands around the world caused by climate changes and human activities is progressively reducing agriculture 
outputs despite escalating calls for more food (Ahmadi et al. 2018; Isayenkov and Maathuis 2019). In Iran, about 6.5 Mha of croplands are affected by varying degrees of salinity which dramatically effects on crop production. Based on the Stanford Iran 2040 Project's report, many parts of Iran are located on the arid area with more than 70\% annual aridity index (Emadi 2018). Thus, the vast areas of this country will be encounters with serious problems which those occur through soil salinization in near years. At this situation, development of salt tolerant varieties of crop plants can be helped to agricultural productivity.

Sustaining of the membrane potential and cell turgidity have been known as the effective mechanisms involved salt tolerance. On the other hand, these physiological behaviours are strongly influenced by the intercellular ionic hemostasis. Hence, the ionic hemostasis is one of the main tolerance mechanisms and disruption in this phenomenon is known as a primary response to the increasing of sodium ions content $\left(\mathrm{Na}^{+}\right)$in the plant cells (Basu et al. 2020). Munns (1995) declared that salinity stress induces two types of stress on plants. When the salts accumulate around the roots, the water availability will be limited for plant cells and the first phase immediately appearance as the 'osmotic stress'. The main consequence of this phenomenon is the disruption of water transfer from soil to roots and finally decreasing the rate of shoot growth. The second phase will appear through increasing content of cytosolic chloride $\left(\mathrm{Cl}^{-}\right)$and $\mathrm{Na}^{+}$in the developed leaves and it has been known as the 'ionic stress'. In the majority of plant species, $\mathrm{Na}^{+}$ reaches a toxic concentration earlier than $\mathrm{Cl}^{-}$; thus $\mathrm{Na}^{+}$detoxification plays an important role in salt tolerance (Tester and Davenport 2003). Plants possess several protective mechanisms for maintaining ion homeostasis through $\mathrm{Na}^{+}$ exclusion (Munns and Tester 2008). One of the main mechanisms is regulation of balancing between $\mathrm{Na}^{+}$and $\mathrm{K}^{+}$ accumulation in different plant tissues. Indeed, the exclusion of $\mathrm{Na}^{+}$and keeping the high $\mathrm{K}^{+}$concentrations are imperative for maintaining high intercellular $\mathrm{K}^{+}: \mathrm{Na}^{+}$ratio and regulate ionic homeostasis in plants (Singh et al. 2020). It has been demonstrated that impair in germination and establishment of seeding are the foremost effect of ionic toxicity (Purty et al. 2008). Disruption in these key phases of growth and development mainly decreases the water uptake ability and subsequently growth that hastens with time. Ryu et al. (2014) reported that ionic imbalances negatively affected the flowering process and finally disturbing the seed maturation. Inhibit the cell division and accelerate the cell death are other adverse effects of ionic imbalances on plant growth and development under salinity stress (Cheong and Yun 2007). Furthermore, salinity stress with interfering in many physiological and biochemical activities such as restricting uptake water and nutrient into the plant tissues, change in metabolic process, decreasing stomatal conductance, and limiting the photosynthesis activity impedes plant growth and development (Kumar et al. 2009; Tavakkoli et al. 2011; Basu et al. 2017; Radanielson et al. 2018; Basu et al. 2020).

The genetic gain is an important component in plant breeding and plays a key role in development of a programs. The selection based on few traits often is not considered as the most appropriate strategy, because there is no assurance of genetic gains in other important traits (Jahufer and Casler 2015). Hence, breeders often try to gathering various desirable traits in one new genotype would lead to high performance (Olivoto and Nardino 2020). For this purpose, several selection indices have proposed using breeders to select superior genotypes (Caron-Rojas and Crossa 2018). In these approaches, express the economic value of traits and converting them into realistic economic weightings are the main challenges which often limited breeders in choice of the best genotypes (Bizari et al., 2017). To solve this 
limitation, Olivoto and Nardino (2020) has been introduced a new multi-trait index based on factorial analysis and genotype-ideotype distance (MGIDI). This index focus on the selection of superior genotypes where multiple traits have been measured. Olivoto et al. (2021) used the MGIDI index to select superior strawberry genotypes, and furthermore they showed that this this index can simultaneously considers many traits and finally evaluate the strengths and weakness of the test genotypes.

In spite of this fact that breeders assessed various agronomic characters in their breeding programs, they always consider the yield performance as the target trait. Grain yield is a quantitative traits and mainly is affected by environmental fluctuations. When experimental genotypes are tested in multiple environments (more one location or years), in addition to the main effects of environment (E) and genotype (G), a tow-way interaction between them arises as a third effect (GEI). The GEI effect is very important for agronomist and breeders. Because this effect reduces the correlations among genotypic and phenotypic values and confuses the selection of superior genotypes across different environment (Pour-Aboughadareh et al. 2019). In such circumstances, it is necessary to use approaches of adaptability and stability analyses to select superior genotypes across different environments. Investigation of genotypes in the multi-environment trials (MET) allows breeders and agronomist to identification of ideotypes that reveal a specific adaptability to several environments (Olivoto et al. 2019). In order to interpret GEI effect in METs, numerous statistical approaches and model have been developed. The additive main effect and multiplicative interaction (AMMI) analysis is one of the best model which widely used for choose of the superior genotypes in barley and other crop plants (Khalili and Pour-Aboughadareh 2016; Paderewski et al. 2016; Vaezi et al. 2017; Vaezi et al 2018; Baraki et al. 2020; Ahakpaz et al. 2021). Although this analysis have many advantages in explain GEI, disability of this model in analyzing the structure of the linear mixed-effect model (LMM) caused to arrival new models. To circumvent these issues, Olivoto et al. (2019) proposed a novel model namely WAASB (weighted average of absolute scores from the singular value decomposition of the matrix of BLUP for GEI effects generated by a LMM) for better characterizing ideal genotypes based on both yield performance and stability. This model combining the features of AMMI and BLUP models in a unique index. Recently, Zuffo et al. (2021) and Ahakpaz et al. (2021) used the proposed statistic in selection of soya bean and barley genotypes, respectively, and accentuated the usefulness of this parameter in choosing high yielding and stable genotypes.

With this in mind, the main objective of the current work was to use of the multi-trait genotype-ideotype distance index (MGIDI) for evaluate of a set of new advanced barley genotypes under two control and salinity conditions. Furthermore, the grain yield stability was analyzed using the WAASB index.

\section{Materials and methods}

Plant material

For the experiments described in this research, we used a set of 20 genotypes of barley including 18 breeding lines and two Iranian commercial cultivars. The breeding lines were derived from different crosses among Iranian landraces and international parent that provided from the International Center for Agricultural Research in the Dry Areas (ICARDA). Additional information on the pedigrees of selected genotypes is found in Supplementary Table S1.

Experimental conditions at the seedling stage 
A greenhouse experiment was carried out in 2019-2020 at the Cereal Research Department, Seed and Plant Improvement Institute (SPII), Karaj, Iran. All genotypes were investigated in a hydroponic system at an optimal growing photoperiod $(16 \mathrm{~h}$ light, $8 \mathrm{~h}$ dark $)$ and temperature $\left(25^{\circ} \mathrm{C}\right.$ day, $20 \pm 2^{\circ} \mathrm{C}$ night $)$ conditions. All planting trays were placed into tanks filled with $20 \mathrm{~L}$ of Hoagland nutrient solution (consisting of $\left(\mathrm{NH}_{4}\right) \mathrm{H}_{2} \mathrm{PO}_{4}\left(115 \mathrm{~g} \mathrm{~L}^{-1}\right), \mathrm{KNO}_{3}$ $\left(107 \mathrm{gL}^{-1}\right), \mathrm{Ca}\left(\mathrm{NO}_{3}\right)_{2} \cdot 4 \mathrm{H}_{2} \mathrm{O}\left(236 \mathrm{gL}^{-1}\right), \mathrm{MgSO}_{4} .7 \mathrm{H}_{2} \mathrm{O}\left(246 \mathrm{gL}^{-1}\right)$, Fe-EDTA $\left(5 \mathrm{gL}^{-1}\right), \mathrm{H}_{3} \mathrm{BO}_{3}\left(0.38 \mathrm{gL}^{-1}\right), \mathrm{ZnSO}_{4} .7 \mathrm{H}_{2} \mathrm{O}$ $\left(0.22 \mathrm{gL}^{-1}\right), \mathrm{MnSO}_{4} .4 \mathrm{H}_{2} \mathrm{O}\left(1.02 \mathrm{~g} \mathrm{~L}^{-1}\right), \mathrm{CuSO}_{4} .5 \mathrm{H}_{2} \mathrm{O}\left(0.08 \mathrm{~g} \mathrm{~L}^{-1}\right)$, and $\left(\mathrm{NH}_{4}\right)_{6} \mathrm{MO}_{7} . \mathrm{O}_{24} .4 \mathrm{H}_{2} \mathrm{O}\left(0.02 \mathrm{~g} \mathrm{~L}^{-1}\right)$ (Hoagland and Arnon 1950). Two separated experiments including $0 \mathrm{mM} \mathrm{NaCl}$ as the control conditions and $200 \mathrm{mM} \mathrm{NaCl}$ ( $20 \mathrm{dS} \mathrm{m}^{-1}$ ) as the stress conditions were performed based on a randomized block design with three replications. During germination and seedling growth and development, nutrient solutions in hydroponic systems were changed every 2 days. Aeration was supplied to each tank with a central air pump and two large airstones. The aeration was switched on 24 hours after planting. In the salinity experiment, salinity stress was started by adding $\mathrm{NaCl}$ in five steps to reach $200 \mathrm{mM}$ at the third-leaf stage, while control seedlings (non-stressed experiment) only received nutrient solution. After 21 days of growth and salinity treatment, several physiological traits were measured.

To obtain the fresh weights of roots and shoots (RFW and SFW, respectively), all seedlings of each genotype were harvested and weighted using a digital balance apparatus with an accuracy of $\pm 0.001 \mathrm{~g}$. Then, the root and shoot dry weights (RDW and SDW, respectively) were determined by a hot air oven at $70^{\circ} \mathrm{C}$ for 48 hours. The water relative content (RWC) was measured using the leaf samples of each genotype according to the following equation (Blum 2010):

$$
\text { RWC } \%=[\text { fresh weight }- \text { dry weight }] /[\text { turgid weight }- \text { dry weight }] \times 100
$$

A handheld chlorophyll meter device (Minolta SPAD-502, Tokyo, Japan) was used to detect the relative chlorophyll content (SPAD index). To measure leaf gas exchange, a clean and healthy leaf from each genotype was selected. The net photosynthetic rate $\left(P_{N}\right)$, stomatal conductance $(G s)$, and transpiration rate $\left(T_{E}\right)$ were measured on a developed leaf using an infrared gas analyzer (LICOR, Lincoln, USA). During the measuring of traits, light intensity was fixed from 800 to 1800 lx. All measurements were recorded between 9 AM and $3 \mathrm{PM}$ at a fixed flow rate of $400 \mu \mathrm{mol} \mathrm{s}$. The membrane stability index (MSI) was measured as proposed by Sairam et al. (2002). Leaf samples ( $0.1 \mathrm{~g}$ ) firstly were cut and floated in $10 \mathrm{ml}$ of double-distilled water in two separate sets. One set was maintained at $40^{\circ} \mathrm{C}$ for 30 minutes and another set at $100^{\circ} \mathrm{C}$ for 15 minutes in a boiling water bath. The electronic conductivity of each set (C1 and $\mathrm{C} 2$, respectively) was measured by a conductivity meter (AQUALYTIC, Germany) and MSI was then measured by the following equation:

$$
\mathrm{MSI}=[1-(\mathrm{C} 1 / \mathrm{C} 2)] \times 100
$$

To analysis of ionic concentrations in plant tissues, the root and shoot samples $(10 \mathrm{mg})$ were digested with $10 \mathrm{ml} 0.5$ $\mathrm{N}$ nitric acid and maintained at $85^{\circ} \mathrm{C}$ for 2 hours in a boiling water bath. The digested plant material was filtered and analyzed for $\mathrm{Na}^{+}$and $\mathrm{K}^{+}$concentrations ( $\mathrm{mmol} \mathrm{g}^{-1}$ dry weight (DW)) using flame photometry (Sherwood Scientific Flame Photometer 420, UK). Furthermore, the $\mathrm{Na}^{+}$and $\mathrm{K}^{+}$translocation from roots to shoots were estimated following the method of Saqib et al. (2005) using the formulae below: 


\section{Root-to-shoot $\mathrm{Na}^{+}$translocation $(\mathrm{RTSN})=\left[\right.$ shoot $\mathrm{Na}^{+}$content $(\mathrm{mmol}) / \operatorname{root} \mathrm{Na}^{+}$content $\left.(\mathrm{mmol})\right]$ \\ Root-to-shoot $\mathrm{K}^{+}$translocation $(\mathrm{RTSK})=\left[\right.$ shoot $\mathrm{K}^{+}$content $(\mathrm{mmol}) / \operatorname{root} \mathrm{K}^{+}$content $\left.(\mathrm{mmol})\right]$}

\section{Field trial experiments}

The multi-location trials were performed at three saline regions of Iran (Yazd, Birjand and Esfahan) during two consecutive years (2018-2019 and 2019-2020) cropping seasons. All regions have a moderate climate and located in the tropical zones of Iran. In all trials, the salinity level of soil and irrigation water were tested during the experimental period from seed sowing to harvesting. The mean salinity of soil and irrigation water was 12 and $10 \mathrm{dS} \mathrm{m}^{-1}$, respectively. Sowing and crop managements in all regions were done based on experts' advice. At each research station, genotypes were investigated in a randomized complete block design with four replications. Each plot consisted of six 5-m-long rows with intra-row spacing of $20 \mathrm{~cm}$. Sowing was performed by an experimental plot planter (Wintersteiger, Austria) with a plant density of 400 seeds per square meter. At harvest time, plots were harvested using experimental combine (Wintersteiger, Austria). Finally, grain yields were measured and data were converted to tonnes per hectare.

\section{Statistical data analysis}

In the greenhouse experiment, a combined analysis of variance (ANOVA) was performed using SAS software ver. 9.1 (SAS, 2011) to test the effects of environment [control and salinity] and genotype main effects and their interaction. The relative change (RC) due to salinity stress was computed for each trait according to Pour-Aboughadareh et al. (2020). Principal component analysis (PCA) was computed to detect interrelationships among measured traits using 'factoextra' package of R software 4.0.3. To grouping investigated barley genotypes and also measured traits a hierarchical cluster analysis was computed based on the Euclidean distances using 'ggdendro' and 'ggplot2' packages of R software (R Core Team 2020).

The multi-trait genotype-ideotype distance index (MGIDI) was used to rank the genotypes based on information of multiple traits as proposed by Olivoto and Nardino (2020). In the first step, each trait $\left(\mathrm{rX}_{\mathrm{ij}}\right)$ were rescaled using following equation:

$$
\mathrm{rX}_{\mathrm{ij}}=\frac{\eta_{n j}-\varphi_{n j}}{\eta_{o j}-\varphi_{o j}} \times\left(\theta_{i j}-\eta_{o j}\right)+\eta_{n j}
$$

where $\varphi_{o j}$ and $\eta_{o j}$ are the original minimum and maximum values for the trait $j$, respectively; $\varphi_{n j}$ and $\eta_{n j}$ are the new minimum and maximum values for trait $j$ after rescaling, respectively; and $\theta_{i j}$ is the original value for $j$ th trait of the $i$ th genotype. The values for $\eta_{n j}$ and $\varphi_{n j}$ are chosen as follows: for the traits in which positive gains are desired $\varphi_{n j}=0$ and $\eta_{n j}=100$ should be used, while for the traits in which negative gains are desired $\varphi_{n j}=100$ and $\eta_{n j}=0$ should be used (Olivoto and Nardino 2020). In the next step, a factor analysis (FA) was performed to account for the dimensionality reduction of the data and relationships structure. This analysis was performed according to following model:

$$
\mathrm{F}=\mathrm{Z}\left(\mathrm{A}^{\mathrm{T}} \mathrm{R}^{-1}\right)^{\mathrm{T}}
$$


where $\mathrm{F}$ is a $g \times f$ matrix with the factorial score; $\mathrm{Z}$ is a $g \times p$ matrix with the rescaled means; $\mathrm{A}$ is a $p \times f$ matrix of canonical loading, and $\mathrm{R}$ is a $p \times p$ correlation matrix between the traits. Furthermore, $g, f$, and $p$ indicates the number of genotypes, factor retained, and measured traits, respectively. In the third step, a $[1 \times p]$ vector was considered as the ideotype matrix. In the last step Euclidean distance between the scores of genotypes and the ideal genotypes was computed as MGIDI index using following equation:

$$
\text { MGIDI }=\sum_{\mathrm{j}=1}^{\mathrm{f}}\left[\left(\gamma_{i j}-\gamma_{j}\right)^{2}\right]^{0.5}
$$

where $\gamma_{i j}$ is the score of the $i$ th genotype in the $j$ th factor $(i=1,2, \ldots, t ; j=1,2, \ldots, f)$, being $t$ and $f$ the number of genotypes and factors, respectively; and $\gamma_{j}$ is the $j$ th score of the ideal genotype. The genotype with the lowest MGIDI is then closer to the ideal genotype and thus indicates desired values for all the measured traits. The selection differential for all traits was performed considering a selection intensity of $\sim 20 \%$. Data manipulation and the index computation were performed in the R software using the 'metan' package (Olivoto and Lucio 2020).

In METs, the grain yield data of barley genotypes were subjected to the additive main effects and multiplicative interaction (AMMI) analysis as proposed by Zobel et al. (1988) using 'metan' package of R 4.0.3. Combining feature of AMMI and BLUP methods was computed as proposed by Olivoto et al. (2019). In this way, statistic of weighted average of absolute scores of the genotype (WAASB) was used as follows:

$$
W A A S B=\sum_{n=1}^{p}\left|I P C A_{g n} \times E P_{n}\right| / \sum_{n=1}^{p} E P_{n}
$$

where $I P C A_{g n}$ is the score of the genotype $g$ in the $\mathrm{n}^{\text {th }}$ interaction principal component axis (IPCA), and $E P_{n}$ is the amount of the variance explained by the $\mathrm{n}^{\text {th }}$ IPCA. The genotypes with lower WAASB were identified as stable genotype. This index was calculated using 'metan' package of R software.

\section{Results}

\section{Root and shoot features}

The results of combined analysis of variance (ANOVA) showed that the effect of salinity treatment was highly significant for root and shoot fresh weights (RFW and SFW, respectively) and root and shoot dry weights (RDW and SDW, respectively). Also, significant differences for RFW, SFW and SDW were observed among the investigated genotypes. However, the interaction effect between salinity stress and genotypes was significant only for SFW (Table 1). RFW drastically decreased (60.43\%) in all barley genotypes when exposed to $200 \mathrm{mM} \mathrm{NaCl}$ salinity compared to control (Table 3). The maximum reduction of RFW under salinity stress was observed in G19 (78.67\%), G17 (75.64\%), G3 (74.10\%), G6 (71.49\%), G13 (70.92\%), and G2 (70.13\%). However, the lowest reduction had been displayed by G11 (43.48\%), G15 (45.83\%), G9 (47.13\%), and G14 (47.85\%), similar to salt-tolerant checks G1 (46.49\%) and G20 (22.83\%) (Table 3). Salinity stress significantly affected the RDW in the barley seedlings by $48.75 \%$ reduction compared with control conditions (Table 3). The minimum reduction of RDW were found in the check genotype G20 (4.16\%) followed by G14 (26.62\%), G3 (32.02\%), G12 (34.77\%), G11 (35.80\%), and G2 (35.94\%), respectively, whereas the maximum reduction was found in genotypes G6 (61.06\%), G13 (64.57\%), and 
G17 (70.59\%). Under salinity stress conditions, the mean of SFW and SDW across the 20 investigated genotypes reduced by $76.63 \%$ and $61.02 \%$, respectively, compared with their respective values in control conditions. All tested genotypes showed the high rate of reduction (> 50\%) for SFW and the maximum reductions were found in genotypes G19 (86.71\%), G17 (85.60\%), G20 (82.62\%), G18 (81.69\%), G16 (81.51\%), G1 (81.35\%), and G7 (75.78\%). Only one genotype G7 (50.35\%) showed the minimum reduction in SFW compared with other genotypes (Table 3). Furthermore, the significant reduction of SDW was found in most of the barley genotypes under salinity stress conditions. In this regard, a slight reduction of SDW was observed in genotypes G4 (41.82\%), G7 (46.57\%), G20 (48.31\%), and G3 (49.04\%), while the most reduction was recorded in G1, G6, G17, and G18 (Table 3).

\section{Relative water content and membrane stability index}

ANOVA for the relative water content (RWC) and membrane stability index (MSI) showed the significant effects of salinity conditions and genotypes. The two-way interaction effect between salinity and genotype effects was significant for RWC (Table 2). The overall means of 20 barley genotypes for RWC and MSI showed a slight reduction (15.53\% and $19.45 \%$, respectively) at $200 \mathrm{mM} \mathrm{NaCl}$ conditions (Table 2). Genotype numbers G6 (2.46\%), G8 (2.65\%), G15 (4.77\%), G1 (5.26\%), G16 (6.10\%), and G20 (7.74\%) showed the minimum reduction of RWC in relative to other genotypes, whereas genotypes G3 (33.18\%), G4 (32.30\%), G5 G10 (28.63\%), and (26.51\%) showed the maximum reductions (Table 2). In regard to MSI parameter, we showed a slight increase in genotype G5 (0.51\%) and G18 (0.94\%). However, the lowest reductions were observed in genotypes G10 (5.52\%), G3 (8.46\%), and G16 $(10.55 \%)$ (Table 2).

\section{Relative chlorophyll and leaf gas exchanges}

Salinity significantly influenced the relative chlorophyll content (SPAD value), net photosynthesis rate $\left(P_{N}\right)$, stomatal conductance $\left(G_{S}\right)$, and transpiration rate $\left(T_{E}\right)$. The results of ANOVA also showed highly significant differences among the tested barley genotypes for SPAD and $T_{E}$. On the other hand, the interaction effect between salinity conditions and genotype was only significant for $T_{E}$ (Table 3). Under salinity stress conditions, genotypes G4 (1.34\%), G15 (2.72\%), and G6 (4.13\%) showed a minimum reduction of SPAD. Furthermore, genotypes G5 (3.51\%) and G10 $(4.76 \%)$ indicated a reverse pattern for this index and showed a slight increasing in their leaf chlorophyll content. The highest reduction in SPAD was observed in genotypes G11 (28.85\%), G3 (25.60\%), G7 (21.57\%), and G9 (21.77\%) (Table 3). Although there were no significant differences among the tested genotypes for $P_{N}$ and $G_{S}$ traits, genotypes G14 (2.99\% / 77.77\%), G19 (3.23\% / 65.35\%), G20 (4.74\% / 66.04\%), G12 (6.07\% / 40\%), G2 (6.21\% / 54.55\%), and G18 (6.48\% / 23.65\%) showed the minimum reduction for these traits. Similarly, the minimum reduction of $T_{E}$ under salinity conditions was observed in the check genotypes G1 (5.79\%), G18 (3.35\%), G12 (41.59\%), G4 (55.34\%), and G19 (55.92\%). The highest reduction of $T_{E}$ was recorded in genotypes G10 (97.98\%), G3 (95.81\%), G9 (94.91\%), G13 (87.02\%), and G6 (86.11\%) (Table 3).

\section{Ionic concentrations}

Based on ANOVA, the highly significant differences for both factors [salinity conditions and genotypes] and their interaction were observed for $\mathrm{Na}^{+}$and $\mathrm{K}^{+}$concentrations in root ( $\mathrm{RN}$ and $\mathrm{RK}$, respectively), $\mathrm{Na}^{+}$and $\mathrm{K}^{+}$concentrations in shoot (SN and SK, respectively), as well as for their $\mathrm{K}^{+}: \mathrm{Na}^{+}$ratios (RKN and SKN, respectively). Moreover, the 
main effects and their interaction were significant for root-to-shoot $\mathrm{Na}^{+}$translocation (RTSN) and root-to-shoot $\mathrm{K}^{+}$ translocation (RTSK) (Table 1). Salinity stress significantly increased RN and SN compared with control conditions (854.56\% and 91.68\%, respectively). Two genotypes G8 and G11 showed a reduction for the $\mathrm{Na}^{+}$content in their roots, and the other hand G20 (11.97\%), G5 (45.81\%) and G13 (55.89\%) showed the minimum increasing for NR than other genotypes. The highest increase in RN was recorded in G1 (379.69\%), G10 (292.01\%), G4 (250.63\%), G6 (245.96\%), and G9 (223.78\%) (Table 3). All genotypes displayed a high range of variability for $\mathrm{Na}^{+}$content in their leaves. The maximum relative change for SN was observed in genotypes G20 (2652.68\%) followed by G3 (1135.95\%), G1 (1110.11\%), G17 (772.22\%), and G14 (1048.34\%). On the other hand, G2, G8, G9, G19, and G16 showed the minimum changes in their SN than other genotypes $(375.76 \%, 408.08 \%, 486.35 \%, 586.91 \%$, and $634.06 \%$, respectively) (Table 3). The pattern of $\mathrm{K}^{+}$concentration in root and shoot tissues was different from $\mathrm{Na}^{+}$ concentrations patterns. Salinity stress severely decreased RK (91.23\%) across the 20 tested barley genotypes (Table 2). The maximum reduction of RK was found in G17 (95.63\%), G18 (95.14\%), G1 (94.38\%), G7 (93.59\%), and G6 (93.52), whereas G12 (80.07\%), G20 (87.04\%), G8 (87.61\%), G4 (89.34\%), and G10 (89.49\%) reflected a minimum reduction of RK under salinity stress conditions (Table 4 ).

Salt stress negatively also affected the SK in the barley seedlings (46.89\%) (Table 4). Although two genotypes G7 and G18 showed an increasing trend in $\mathrm{K}^{+}$content in their leaves, other genotypes reflected a reduction pattern due to salinity stress. The maximum reduction was observed in G2 (73.45\%), G6 (63.55\%), G4 (60.62\%), G18 (60.08\%), and G16 (58.43\%), while G11, G17, G20, and G13 by 10.04\%, 10.61\%, 36\%, and 37.14\% reduction were recognized as the best genotypes under salt stress situations (Table 4). The mean of RKN and SKN of barley seedlings had decrease due to salinity stress by $96.11 \%$ and $94.70 \% \%$ compared with control conditions (Table 4). Under salinity conditions, genotypes G11 (84.77\%), G8 (86.29\%), G20 (88.36\%), G12 (89.06\%), and G13 (94.44\%) showed the minimum reduction of RKN, whereas the maximum reduction was estimated by G1 (98.86\%), G6 (98.24\%), G9 (97.83\%), G7 (97.82\%), and G18 (97.73\%), respectively. In terms of SKN, genotypes G7 (84.60\%), G18 (86.05\%), G11 (90.90\%), G8 (91.12\%), and G17 (91.95\%) reflected the minimum reduction. On the other hand genotypes G20, G6, G4, G3, and G1 with a reduction of $97.84 \%, 96.84 \%, 96.83 \%, 96.65 \%$, and $96.18 \%$, respectively, were identified as the weak genotypes for maintaining $\mathrm{K}^{+}$ions in their leaf tissue (Table 4). Salinity stress conditions significantly increased the transfer of both $\mathrm{Na}^{+}$and $\mathrm{K}^{+}$ions from roots to shoots. Under salinity conditions, the mean of RTSN across the all investigated barley genotypes increased by $356.27 \%$ compared with control conditions, and genotypes G9 (92.45\%), G1 (131.54), G10 (149.25\%), G2 (162.86\%), and G6 (192.21\%) exhibited the minimum relocation of $\mathrm{Na}^{+}$, while G20, G11, G3, G17, and G12 had the highest ability in movement $\mathrm{Na}^{+}$(increasing percentage of $2227.57 \%$, $1689.28 \%, 689.31 \%, 558.38 \%$, and $476.34 \%$, respectively, compared with control conditions) (Table 4). The mean of RTSK was increased by $677.46 \%$ due to salinity in relative to corresponding value under control conditions (Table 4). Among the tested genotypes, G18 (2592.27\%), G7 (2124.16\%), G17 (2094.08\%), G11 (997.78\%), and G6 (964.35\%) were identified as the genotypes with high ability in the transfer of $\mathrm{K}^{+}$ions in different organs. The lower ability in relocation of this ion was found in genotypes G20 (166.63\%) followed by G8 (259.13\%), G10 (372.46\%), G15 (388.23\%), and G16 (398.02\%) (Table 4).

\section{Principal component analysis and hierarchical clustering pattern}


The principal component analysis (PCA) was computed on the experimental data set including 18 physiological variables and 20 barley genotypes with aim of enhancing the discrimination power to grouping the measured traits based on the relationships among them under salinity stress conditions. The results showed that the first six components (PCs) with eigenvalues $\geq 1$ accounted for $82.01 \%$ of the total variation. The first PC accounted for $27.88 \%$ of the total variation in the data and significantly correlated with RDW, SDW, RFW, SN, RK, SKN, RKN, RTSN, and RTSK. The PC2 explained $17.42 \%$ of the total variation and mainly influenced by SFW, $G_{S}$, SN, RN, SK, RTSN, and RTSK. The PC3 accounted for $13.68 \%$ of the total variation and significantly correlated with RWC, $G_{S}$, and $T_{E}$. The PC4 and PC5 accounted for $8.67 \%$ and $8.17 \%$ of the total physiological variation, respectively. The PC4 mainly correlated with $P_{N}$, RFW, SPAD, and MSI, while PC5 showed a slight correlation with RDW, RN, RK, and SKN. The PC6 only justified $6.18 \%$ of the total variation and there was no considerable correlation between it with the measured traits (Fig. 1A). Since the first two PCs showed the highest percentage of variance, therefore they were used to create a PCA-based biplot. Based on the biplot, all measured grouped into four clusters (I-IV): cluster I included of RK, SN, RKN, RTSN, RFW, RDW, and SDW; cluster II comprised of RK, RFW, RDW, SDW, and SFW; cluster III consisted of $P_{N}, G_{S}, T_{E}$, RWC, RN, SK, SFW, SPAD, and MSI; cluster IV contained all traits except RKN, RK, RFW, RDW, SDW, and SFW (Fig. 1B).

The two-side dendrogram obtained from cluster analysis showed that all investigated barley genotypes and measured traits were grouped into different sub-clusters (Fig. 2). As per results, genotype G20 showed the positive linkage with several traits such as $P_{N}, \mathrm{SK}, \mathrm{SN}, \mathrm{RTSN}, \mathrm{RFW}, \mathrm{RDW}, \mathrm{SDW}, \mathrm{RK}, \mathrm{RKN}$, and RWC and therefore it was separated from other genotypes in the distinct cluster. The result of cluster analysis showed that all investigated genotypes separated into different groups. Genotypes G18, G8, G15, and G17 showed a similar pattern for some of traits, hence they were grouped into same sub-cluster. Remain genotypes were fell into the distinct cluster, however, some of them placed in a separate sub-cluster due to their similar linkages with various physiological traits. For instance, G5, G9, G11, G13, G14, and G19 showed the same linkage for most of the traits and created a distinct sub-sub-cluster.

\section{Selection of salt-tolerant genotypes}

The multi-trait genotype-ideotype distance (MGIDI) index was calculated to select the salt-tolerant genotypes with respect to considering all measured traits. Based on results, a highly significant genotypic effect was found for 10 measured traits including MSI, RWC, SFW, $G_{S}, \mathrm{PK}, \mathrm{SK}, \mathrm{RKN}, \mathrm{SN}, \mathrm{RN}$, and RTSN (Table 5). The broad-sense heritability $\left(h^{2}\right)$ ranged from 0.56 (for RK) to 0.92 (for SN). High values of heritability were estimated for all filtered traits which suggest good prospects of selection gains for these traits. The result of PCA showed that the first four components with eigenvalues $\geq 1$ accounted for $79.80 \%$ of the total variation among the traits (data not shown). Among selected traits, traits RN, SN, and RK showed the highest genetic gains (19.60\%, 10.60\%, and 6.92\%, respectively). However, only MSI showed undesired selection gain (-2.81\%). In general, the MGIDI index provided the higher total gains, i.e. $42.91 \%$ for traits that wanted to increase and of $-10.62 \%$ for traits that wanted to decrease. The genotypes selected using the MGIDI index were G12, G14, G6, and G7 (Fig. 3A). The strengths and weaknesses of selected genotypes showed that the first factor (FA1) had the highest contribution for genotypes G6, G7, and G14. The FA2 showed the highest contribution for genotype G12. The FA3 indicate the highest contribution for genotypes G6 and G7. Finally, the FA4 represented the highest contribution for genotypes G6 and G12 (Fig. 3B). 


\section{Grain yield performance and stability}

The AMMI analysis of variance reveled that main effects due to environment (E), genotype (G), and GE interaction (GEI) were significant (Table 6). The E, G, and GE interaction accounted for $26 \%, 12 \%$, and $22 \%$ of the total variation. This analysis further divided the GEI's sum of squares into four interaction principal components (IPCA1-IPCA4) and residual term. All IPCAs were significant and explained 41.3\%, 32.2\%, 17.3\%, and 9.1\% of the total variation due to the GEI, respectively. The mean yield varied between 3.24 tonnes $^{-1}$ at Yazd in the first year (YZD2) to 4.73 tonnes $\mathrm{h}^{-1}$ at Birjand in the second year (BRJ2) (Table 6). On the other hand, there was a crossover ranking of investigated genotypes across the test environments. The WAASB statistic was used to better characterizing ideal genotypes based on both yield performance and stability. For this purpose, a biplot was rendered based on the WAASB and mean grain yields of genotypes. The first quadrant included YZD1 environment as well as, genotypes G9, G17, G19, and G20. These genotypes and environment showed lower grain yield compared with the average grain yields; hence they have the largest role in GEI. Genotypes G1 and G2 along with environments ESF1, BRJ1, and BRJ2 were placed in the second quadrant. Similar to the previous section, these genotypes have an acceptable performance and the other hand environments have a big role in GEI. Besides, the environments placed in this quadrant provide aboveaverage production; hence they deserve special attention to discriminate the high-yielding genotypes. The G3, G8, G10, G11, and G13 genotypes with lower grain yield than average yields, along with the YZD2 environment fell down in the third quadrant. Environment YZD2 with low performance showed the lowest discrimination power in GE interaction. However, the $W A A S B$ values for these genotypes and environment was minimum. The fourth part of biplot comprised the rest of genotypes. Hence, G4, G5, G6, G7, G12, G14, G15, G16, and G18 genotypes with low WAASB values and high performance were identified as most stable genotypes (Fig. 4). As a general result, G7, G8, G12, G14, and G16 with the lowest values of $W A A S B$ index were identified as the superior genotypes. Furthermore, this result was confirmed with minimum values of $A S V, E V, S P I C$, and $Z a$ stability statistics for the selected genotypes (Table 7).

\section{Discussion}

In the current study, various physiological traits were assessed in 20 advanced genotypes of barley at the early growth stage to investigate their relative tolerance abilities under severe salinity conditions. Moreover, the yield performance and it stability in the investigated barley genotypes were assessed across different saline regions of Iran. As expected, we observed a high significant effect of salinity stress on various growth and physiological traits in the investigated barley genotypes (Table 1). Moreover, all genotypes were severely affected by salt treatment when compared with control conditions. However, some genotypes with the minimum reduction in growth and physiological features showed a relative ability to cope with salinity effects (Tables 2-4). Several studies reported similar results in barley and other crops (Tavakkoli et al. 2010; Ahmadi et al. 2018; Rajeswari et al. 2019; Ahmadi et al. 2020). The root system is the first plant organ that encounter directly in contact with the saline solutions in the soil and gets damage (Alam et al. 2015; Rasel et al. 2020). When roots become severely damaged, shoots growth is restricted due to the disturbance of water nutrients uptake through xylem loading in the root. Furthermore, osmotic stress immediately reduces the leaf area; hence this shows more sensitivity of shoots compared with roots to salinity stress (Rasel et al. 2020). In this study, our findings indicated that root and shoot growth are severely decreased in all genotypes, and in 
contrast G3 displayed a lower root and shoot reduction under stress conditions (Table 2). In this regard, Islam et al. (2009) stated that minimum reduction of root and shoot biomass can be probably due to adopting some physiological and biochemical mechanisms. Salinity-induced reduction of root and shoot biomass has also been observed by several studies in wheat (Ahmadi e al. 2020), Sorghum (Rajabi Dehnavi et al. 2020), barley (Ali and Abbas 2003), purging nut (Abrar et al. 2020), and rice (Rasel et al. 2020).

The relative water content (RWC) has been proposed as a desirable physiological parameter to select plants for their tolerance to salinity (Saeed et al. 2019; Pour-Aboughadareh et al. 2019, 2020). In this study, we observed a 15.53\% reduction in the RWC, in salinity stress conditions when compared with control conditions; however no significant difference was observed among genotypes in control conditions (Table 2). This result may be supported by the effect of higher osmolyte concentration, which may be reflected by the maintenance of higher RWC. However, this result is inconsistent with other reports, which have shown that salinity stress can significantly reduce the intercellular water status in plants (Qin et al. 2010). The membrane stability index (MSI) is another physiological indicator that widely used to estimate potential salinity tolerance in different crops (ElBasyoni et al. 2017; Abrar et al. 2020; Ebrahim et al. 2020). It has been reported that MSI is more effective in screening tolerant genotypes at the early growth stage (Farooq and Azam 2006), since it often affected by lipid peroxidation caused by oxidative stress that results in the production of malondialdehyde (MDA) (Ahmed et al. 2013). Furthermore, MSI is a quantitative trait with a moderate heritability, which has a high genetic correlation with grain yield (Hemantaranjan 2014). In the present study, MSI changed modestly when plants were exposed to salinity stresses relative to control conditions (Table 2). Our results validate that these traits can be the major attributes inducing towards salt tolerance, because these were less affected by salinity stress (Abrar et al. 2020). Moreover, a strong correlation was observed between these physiological parameters (Fig. 1B). As a result, the G16 genotype showed the lower reduction in terms of RWC and MSI traits.

Chlorophyll as a green-colored pigment is a vital component of the photosynthetic apparatus, and its role in capturing light energy, energy transduction, and stabilization of membranes has been investigated extensively (Porcar-Castell et al. 2014; Shah et al. 2017; Shin et al. 2020; Abrar et al. 2020). The relative chlorophyll content is likely to decline under salt treatment compared with control condition. In the present study, chlorophyll content showed the differential pattern during stress treatments. In general, this trait was declined by $11.62 \%$ when compared with the control conditions (Table 3). In this regard, our result was similar to Rangani et al. (2016), who also revealed that the decrease in chlorophyll contents under high salinity levels was ascribed to the fragmentation of chlorophyll structure. As a contrast result, salinity stress slightly increased chlorophyll content in some barley seedlings. This finding is agreement with the results reported in cotton (Higbie et al. 2010), sunflower (Heidari et al. 2014), Thellungiella sals (Goussi et al. 2018), and lettuce (Shin et al. 2020). It has been reported that increasing salt solutions in leaf tissue decreases leaf area index and leads to increase in specific leaf weight (Sohan et al. 1999). Indeed, reduction in leaf area under salinity stress correlated with increasing in leaf thickness, which it in turn lead to increment in chlorophyll content (Papp et al. 1983). On the other hand, Misra et al. (1997) stated that salinity stress could be increased the number of chloroplasts and finally increased the chlorophyll content. However, Husain et al. (2003) reported a positive correlation between SPAD value and concentration of $\mathrm{Na}^{+}$in leaf. In other word, genotypes which maintenance low content of $\mathrm{Na}^{+}$in their leaves showed high relative chlorophyll, whereas genotypes which showed suddenly reduction 
in greenness had high $\mathrm{Na}^{+}$content in their leaves. Hence, we can conclude that there is a makeable association between chlorophyll content and $\mathrm{N}^{+}$concentration. This result was also confirmed by PCA analysis, where there was observed a positive and significant correlation between root $\mathrm{N}^{+}$concentration and SPAD value (Fig. 1B).

The leaf gas exchange analysis showed that salt stress affected stomatal conductance $\left(G_{S}\right)$ and transpiration rate $\left(T_{E}\right)$ (Table 3). Throughout the experiment, the barley seedlings showed a minimum reduction of photosynthesis rate $\left(P_{N}\right)$. Although salinity stress reduced $P_{N}$ compared with control conditions, however no significant difference was observed between treatments and among the investigated genotypes. It has been reported that stomatal behavior directly affect the $P_{N}$ (Yang et al. 2008). During the progress of salinity stress, the huge amount of salts is accumulated in the older leaves. Increasing salt concentration levels result in the leaf greenness took place prematurely, which lead to a limitation in the photosynthesis rate. Consequently, the $P_{N}$ is declined and finally it led to a lower biomass (Flexas et al. 2007). As per results, we observed a positive association among $P_{N}, G_{S}$, and SFW traits (Fig. 1B), which supported the last case. Also, several genotypes such as G2, G12, G19, and G20 showed the minimum reduction of $G_{S}$ and $P_{N}$. Of these, G12 and G19 genotypes along with G1, G4, and G18 showed the minimum reduction of $T_{E}$. The $T_{E}$ is correlated with the normal assimilation of $\mathrm{CO}_{2}$, hence it has an important role in the photosynthesis process (Kamran et al. 2020). Hence, the capability of plants in minimizing reduction of $T_{E}$ could be related to their ability to cope with stress conditions.

Plants tend to maintain high $\mathrm{K}^{+}$concentration instead to $\mathrm{Na}^{+}$in their root and stem. In numerous studies have been showed plants tend to decrease the toxic effects of $\mathrm{Na}^{+}$in their tissues by obtaining sufficient $\mathrm{K}^{+}$contents and excreting more $\mathrm{Na}^{+}$. Potassium is a key macro-nutrient, which active more than 50 enzymes and it has been reported that it contributed in the biosynthesis of chlorophyll pigments (Shabala and Cuin 2003). From chemical viewpoint, both $\mathrm{Na}^{+}$ and $\mathrm{K}^{+}$have a same level of hydration energy and ionic radius. Hence, under saline conditions, $\mathrm{Na}^{+}$ions can easily enter into cell through $\mathrm{K}^{+}$channels which located at cell membranes. This is in turn of leads to the higher cytoplasmic content of $\mathrm{Na}^{+}$and decline the $\mathrm{K}^{+}: \mathrm{Na}^{+}$ratio, which finally affects plant growth and development. Hence, one of the plant's defense strategies to decreasing negative effects of accumulation $\mathrm{Na}$ either minimizing $\mathrm{K}$ loss is maintenance high $\mathrm{K}^{+}: \mathrm{Na}^{+}$ratio in the cytoplasm (Adolf et al. 2013). In this study, we found that both root and shoot $\mathrm{K}^{+}$contents (RK and SK, respectively) decreased under salt treatment (Table 4). Furthermore, the root and shoot $\mathrm{K}^{+}: \mathrm{Na}^{+}$ratios also showed a decreasing trend under salinity conditions. Among the investigated barley genotypes, G8 and G11 genotypes showed the lower reduction of RKN and SKN rations. We surmise these genotypes can be serve as superior tolerant genotypes due to good capability in maintaining $\mathrm{K}^{+}$in their root and shoot tissues.

Experienced breeders often try to gathering various desirable traits in one new genotype would lead to high performance. When multiple traits are measured selection of ideotype genotypes often is difficult. In this regard, several multivariate approaches (such as principal component analysis (PCA), factor analysis (FA), and cluster analysis (CA)) and various selection indices (including Smith (1936) and Hazel (1943), the base index (Williams, 1962), the index of Pesek and Baker (1969), and Mulamba and Mock (1978)) widely used to grouping the measured traits and also select the test genotypes, respectively. In the current study, we used a two-way heat map clustering pattern and PCA to grouping test genotypes and measured traits (Figs. 1-2), but we could not select some tolerant genotypes. To facilitate the selection of genotypes with multiple traits, Olivoto and Nardino (2020) recently proposed 
a novel method (multi-trait genotype-ideotype distance index: MGIDI) for genotype selection based on information on multiple traits. Based on results, the barley genotypes were ranked based on information on measured multiple traits (Fig. 3A). The MGIDI index selected genotypes G12, G14, G6, and G7 as the salt-tolerant barley genotypes. Apart from these genotypes, G16 was very close to the cut point, which suggests that this genotype can present interesting features. Hence, the researcher should specially attention to assess genotypes that are very close to the cut point (Olivoto and Nardino 2020). As another result from this analysis, we represented that some physiological traits including MSI, RWC, SFW, GS, PK, SK, RKN, SN, RN, and RTSN have a high broad-sense heritability, which they could be deserve attention to use in future studies with aim of screening the tolerant genotypes at the early growth stage (Table 5). The use of the MGIDI index in the investigation of plant crops is expected to rapidly expand. Likewise, Olivio et al. (2021) used this index for choosing ideal strawberry genotypes.

In the current study, we tested the investigated barley genotypes across different five locations in saline regions of Iran. The results of AMMI analysis showed a high significant GE interaction for grain yield (Table 6). This result is agreement with almost all similar studies (Khalili and Pour-Aboughadareh 2016; Vaezi et al. 2017; Vaezi et al. 2019; Ahakpaz et al. 2021). With respect to this fact, the response of barley genotypes was very changeable in each environment, we used the WAASB index as a quantitative stability statistic to identify stable genotypes (Table 7). Based on results, the lowest value of $W A A S B$ was estimated for G7, G8, G14, and G16 genotypes. These genotypes also showed the lowest values of $A S V, E V, S P I C$, and $Z a$ stability statistics (Table 7). To better a joint interpretation of stability and productivity, a biplot based on WAASB and grain yield was rendered (Fig. 4). The main advantage of this biplot than AMMI's biplot is that all IPCA axes are used, hence allowing that GEI patterns not retained in IPCA1 be considered in the genotypes' ranking (Olivo et al. 2019). Indeed, this biplot may be helpful in identifying highly productive and broadly adapted genotypes. Among selected genotypes, only one genotype G8 showed association with one environment (YZD2), whereas remain genotypes did not depend on any environment.

Selection approaches in METs are always interest to barley breeders, but it affected mainly by the strong GE interaction that leads to the reduce yield potential of genotypes across environments (Zuffo et al. 2021). Nowadays, the agricultural systems have encounter to demands for more feed and food due to high climate changes. One of the approaches to solve of this challenge is to obtain desirable genotypes through researches that allow us comprehensive understanding of genetic and plant developmental variation in response to the environmental stresses (Bailey-Serres et al. 2019). Therefore, study responses of various genotypes under stress conditions and evaluation of their yield stability are two important objectives, which should be considered. The integration of these researches provided a context to appearance technological solutions to these studies.

\section{Conclusion}

Variation in physiological traits of seedling plants are key components in the determination of the scale of salinity tolerance in plant species. Hence, the early growth stage may better reveals the physiological and biochemical characteristics of different genotypes. In the present study, we showed genetic variability in terms of several physiological traits among a set of barley advanced lines under salinity stress conditions. Using the MGIDI index, we 
could select as the most desirable G6, G7, G12, G14, and G16 among the 20 investigated genotypes. Considering the yield potential of tested genotypes in MET experiments, we have shown the WAASB index can be used as a powerful index to identify the stable and high yielding genotypes. Using this index, genotypes especially G7, G8, G14, and G16 were selected as the stable genotypes and hence can be recommended for cultivation under salinity conditions. Moreover, we have presented a positive relationships between results obtained from MGIDI and WAASB indices, so that both procedures simultaneously selected several desirable genotypes such as G7, G14, and G16 with high rate of salt tolerance as well as with high stability across different saline regions. Overall, our results provides new insights into the screening nurseries in breeding programs to improve salt tolerance in barley. Hence, these methods can be served as the powerful tools to develop better recommendation strategies.

\section{Acknowledgements}

The authors acknowledge the lab facilities support (No. 2-03-03-236-980895) from the Seed and Plant Improvement Institute (SPII), Agricultural Research, Education and Extension Organization (AREEO), Iran.

\section{Declaration of Competing Interest}

The authors declare that they have no known competing financial interests or personal relationships which have, or could be perceived to have, influenced the work reported in this article.

\section{Compliance with ethical standards}

Conflict of Interest Authors declared no conflict of interest.

\section{References}

Abrar MM, Saqib M, Abbas G, Atiq-ur-Rahman M, Mustafa A, Shah SAA, Mehmood K, Maitlo AA, Hassan M, Sun N, Minggang X (2020) Evaluating the contribution of growth, physiological, and ionic components towards salinity and drought stress tolerance in Jatropha curcas. Plants 9:1574. https://doi.org/10.3390/plants9111574

Adolf VI, Jacobsen S-E, Shabala S (2013) Salt tolerance mechanisms in quinoa (Chenopodium quinoa Willd.). Environ Exp Bot 92:43-54. https://doi.org/10.1016/j.envexpbot.2012.07.004

Ahakpaz F, Abdi H, Neyestani E, Hesami A, Mohammadi B, Nader Mahmoudi K, Abedi-Asl G, Jazayeri Noshabadi MR, Ahakpaz F, Alipour H (2021) Genotype-by-environment interaction analysis for grain yield of barley genotypes under dryland conditions and the role of monthly rainfall. Agric. Water Manag 245:106665. https://doi.org/10.1016/j.agwat.2020.106665

Ahmadi J, Pour-Aboughadareh A, Fabriki Ourang S, Khalili P Poczai P (2020) Unraveling salinity stress responses in ancestral and neglected wheat species at early growth stage: A baseline for utilization in future wheat improvement programs. Physiol Mol Biol Plants 26:537-549. https://doi.org/10.1007/s12298-020-00768-4

Ahmadi J, Pour-Aboughadareh A, Fabriki-Ourang S, Mehrabi AA, Siddique KHM (2018) Screening wild progenitors of wheat for salinity stress at early stages of plant growth: insight into potential sources of variability for salinity adaptation in wheat. Crop Pasture Sci 69:649-658. https://doi.org/10.1071/CP17418

Ahmed IM, Cao F, Zhang M, Chen X, Zhang G, Wu F (2013) Difference in yield and physiological features in response to drought and salinity combined stress during anthesis in Tibetan wild and cultivated barleys. Plos One 8:e77869. https://doi.org/10.1371/journal.pone.0077869

Alam MA, Juraimi AS, Rafi MY, Hamid AA (2015) Effect of salinity on biomass yield and physiological and stemroot anatomical characteristics of purslane (Portulaca oleracea L.) accessions. Biomed Res Int 2015:105695. https://doi.org/10.1155/2015/105695 
Ali RM, Abbas HM (2003) Response of salt stressed barley seedlings to phenylurea. Plant Soil Environ 49:158-162. https://doi.org/10.17221/4107-PSE

Bailey-Serres J, Parker JE, Ainsworth EA, Oldroyd GED, Schroeder JI (2019) Genetic strategies for improving crop yields. Nature 575:109-118. https://doi.org/10.1038/s4158 6-019-1679-0

Baraki F, Gebregergis Z, Belay Y, Berhe M, Zibelo H (2020) Genotype x environment interaction and yield stability analysis of mung bean (Vigna radiata (L.) Wilczek) genotypes in Northern Ethiopia. Cogent Food and Agriculture 6:1-14. https://doi.org/10.1080/23311932.2020.1729581

Basu S, Giri RK, Benazir I, Kumar S, Rajwanshi R, Dwivedi SK, Kumar G (2017) Comprehensive physiological analyses and reactive oxygen species profiling in drought tolerant rice genotypes under salinity stress. Physiol Mol Biol Plants 23: 837-85. https://doi.org/10.1007/s12298-017-0477-0

Basu S, Kumar A, Benazir I, Kumar G (2020) Reassessing the role of ion homeostasis for improving salinity tolerance in crop plants. Physiol Plant https://doi.org/10.1111/ppl.13112

Bizari EH, Pedroso Val BH, Pereira EM, Di Mauro AO, Uneda-Trevisoli S (2017) Selection indices for agronomic traits in segregating populations of soybean. Rev Cienc Agron 48:110-117. https://doi.org/10.5935/18066690.20170012

Blum A (2010) Plant breeding for water-limited environments. Springer, New York

Ceron-Rojas JJ, Crossa J (2018) Linear selection indices in modern plant breeding. Springer, Cham, Switzerland.

Cheong M, Yun D-J (2007) Salt-stress signaling. J Plant Biol 50:148-155. https://doi.org/10.1007/BF03030623

Dasgupta S, Hossain MM, Huq M, Wheeler D (2015) Climate change and soil salinity: the case of coastal Bangladesh. Ambio 44:815-826. https://doi.org/10.1017/age.2017.14

Ebrahim F, Arzani A, Rahimmalek M, Sun D, Peng J (2019) Salinity tolerance of wild barley Hordeum vulgare ssp. spontaneum. Plant Breed 139:304-316. https://doi.org/10.1111/pbr.12770

ElBasyoni I, Saadalla M, Baenziger S, Bockelman H, Morsy S (2017) Cell membrane stability and association mapping for drought and heat tolerance in a worldwide wheat collection. Sustainability 9:1446-1452. https://doi.org/10.3390/su9091606

Emadi MH (2018) Management of salinity in agriculture; Iranian experience. Consultation meeting on saline agriculture, 28 May, FAO, Rome.

Farooq S, Azam F (2006) The use of cell membrane stability (CMS) technique to screen for salt tolerant wheat varieties. J Plant Physiol 163:629-637. https://doi.org/10.1016/j.jplph.2005.06.006

Flexas J, Diaz-Espejo A, Galmés J, Kaldenhoff R, Medrano H, Ribas-Carbo M (2007) Rapid variations of mesophyll conductance in response to changes in $\mathrm{CO}_{2}$ concentration around leaves. Plant Cell Environ 30:1284-1298. https://doi.org/10.1111/j.1365-3040.2007.01700.x

Goussi R, Manaa A, Derbali W, Cantamessa S, Abdelly C, Barbato R (2018) Comparative analysis of salt stress, duration and intensity, on the chloroplast ultrastructure and photosynthetic apparatus in Thellungiella salsuginea. J Photochem Photobiol B 183:275-287. https://doi.org/10.1016/j.jphotobiol.2018.04.047

Hazel LN (1943) The genetic basis for constructing selection indexes. Genetics 28: 476-490. https://doi.org/10.1016/j.jphotobiol.2018.04.047

Heidary A, Bandehagh A, Toorchi M (2014) Effects of $\mathrm{NaCl}$ stress on chlorophyll content and chlorophyll fluorescence in sunflower (Helianthus annuus L.) lines. Yyu J Agr Sci 24:111-120. https://doi.org/10.29133/yyutbd.235924

Hemantaranjan A (2014) Heat Stress Responses and Thermotolerance. Adv Plants Agric Res 1:1-10. https://doi.org/10.15406/apar.2014.01.00012 
Higbie SM, Wang F, Stewart JM, Sterling TM, Lindemann WC, Hughs E, Zhang J (2010) Physiological response to salt $(\mathrm{NaCl})$ stress in selected cultivated tetraploid cottons. Int $\mathbf{J}$ Agron 2010:12. https://doi.org/10.1155/2010/643475

Hoagland DR, Arnon DI (1950) The water-culture method for growing plants without soil. California Agricultural Experiment Station, Circular No. 374. The College of Agriculture, University of California, Berkeley, CA, USA

Husain S, Munns R, Condon AG (2003) Effect of sodium exclusion trait on chlorophyll retention and growth of durum wheat in saline soil. Aust J Agric Res 54:589-597. https://doi.org/10.1071/AR03032

Isayenkov SV, Maathuis FJM (2019) Plant salinity stress: many unanswered questions remain. Front Plant Sci 10:80. https://doi.org/10.3389/fpls.2019.00080

Islam MM, Hoque MA, Okuma E, Banu MNA, Shimoishi Y, Nakamura Y, Murata Y (2009) Exogenous proline and glycinebetaine increase antioxidant enzyme activities and confer tolerance to cadmium stress in cultured tobacco cells. J Plant Physiol 166:1587-1597. https://doi.org/10.1016/j.jplph.2009.04.002

Jahufer MZZ, Casler MD (2015) Application of the Smith-Hazel selection index for improving biomass yield and quality of switchgrass. Crop Sci 55:1212-1222. https://doi.org/10.2135/cropsci2014.08.0575

Kamran M, Parveen A, Ahmar S, Malik Z, Hussain S, Chattha MS, Saleem MH, Adil M, Heidari P, Chen JT (2020) An overview of hazardous impacts of soil salinity in crops, tolerance mechanisms, and amelioration through selenium supplementation. Int J Mol Sci 21:148. https://doi.org/10.3390/ijms21010148

Khalili M, Pour-Aboughadareh A (2016) Parametric and non-parametric measures for evaluating yield stability and adaptability in barley doubled haploid lines. J Agric Sci Tech 18:789-803.

Kumar G, Purty RS, Sharma MP, Singla-Pareek SL, Pareek A (2009) Physiological responses among rassica species under salinity stress show strong correlation with transcript abundance for SOS pathway-related genes. J Plant Physiol 166: 507-520. https://doi.org/10.1016/j.jplph.2008.08.001

Marschner H. (2002) Mineral Nutrition of Higher Plants. 2nd Edition, Academic press, Amsterdam,

Misra AN, Sahl SM, Misra M, Singh P, Meera T, Das N, Har M, Sahu P (1997) Sodium chloride induced changes in leaf growth, and pigment and protein contents in two rice cultivars. Biol Plant 39:257-262. https://doi.org/10.1023/A:1000357323205

Mulamba NN and Mock JJ (1978) Improvement of yield potential of the Eto Blanco maize (Zea maysL.) population by breeding for plant traits. Egypt J Genet Cytol 7:40-51.

Munns R, Schachtman D, Condon A (1995) The Significance of a Two-Phase Growth Response to Salinity in Wheat and Barley. Funct Plant Biol 22:561-569. https://doi.org/10.1071/PP9950561

Munns R, Tester M (2008) Mechanisms of salinity tolerance. Annu Rev Plant Biol 59:651-681. https://doi.org/10.1146/annurev.arplant.59.032607.092911

Mwando E, Han Y, Angessa TT, Zhou G, Hill CB, Zhang XQ, Li C (2020) Genome-wide association study of salinity tolerance during germination in barley (Hordeum vulgare L.). Front Plant Sci 11:118. https://doi.org/10.3389/fpls.2020.00118

Olivoto T, Diel MI, Schmidt D, Lucio ADC (2021) Multivariate analysis of strawberry experiments: where are we now and where can we go? BioRxiv https://doi.org/10.1101/2020.12.30.424876

Olivoto T, Lucio AD (2020) metan: an R package for multi-environment trial analysis. Methods Ecol Evol 11:783789. https://doi.org/10.1111/2041-210X.13384

Olivoto T, Lucio AD, da Silva JA, Marchioro VS, de Souza VQ Jost E (2019) Mean performance and stability in multi-environment trials I: combining features of AMMI and BLUP techniques. Agronomy 111: 2949-2960. https://doi.org/10.2134/agronj2019.03.0220 
Olivoto T, Nardino M (2020) MGIDI: toward an effective multivariate selection in biological experiments. Bioinformatics https://doi.org/10.1093/bioinformatics/btaa981

Paderewski J, Gauch HG, Mądry W, Gacek E (2016) AMMI analysis of four-way genotype xlocation xmanagement xyear data from a wheat trial in Poland. Crop Sci 56:2157-2164. https://doi.org/10.2135/cropsci2015.03.0152

Papp JC, Ball MC, Terry N (1983) A comparative of the effects of $\mathrm{NaCl}$ salinity on respiration, photosynthesis and leaf extension in Beta vulgaris L. (Sugar beet). Plant Cell Environ 6:675-677. https://doi.org/10.1111/13653040.ep11589273

Pesek J and Baker RJ (1969) Desired improvement in relation to selection indices. Can J Plant Sci 1:215-274. https://doi.org/10.4141/CJPS69-137

Porcar-Castell A, Tyystjarvi E, Atherton J, van der Tol C, Flexas J, Pfundel EE, Moreno J, Frankenberg C, Berry JA (2014) Linking chlorophyll a fluorescence to photosynthesis for remote sensing applications: Mechanisms and challenges. J Exp Bot 65:4065-4095. https://doi.org/10.1093/jxb/eru191

Pour-Aboughadareh A, Etminan A, Abdelrahman M, Siddique KHM, Tran LSP (2020) Assessment of biochemical and physiological parameters of durum wheat genotypes at the seedling stage during polyethylene glycolinduced water stress. Plant Growth Regul https://doi.org/10.1007/s10725-020-00621-4

Pour-Aboughadareh A, Omidi M, Naghavi MR, Etminan A, Mehrabi AA, Poczai P, Bayat H (2019) Effect of water deficit stress on seedling biomass and physio-chemical characteristics in different species of wheat possessing the D genome. Agronomy 9:522. https://doi.org/10.3390/agronomy9090522

Pour-Aboughadareh A, Yousefian M, Moradkhani H, Poczai P, Siddique KHM (2019) STABILITYSOFT: a new online program to calculate parametric and non-parametric stability statistics for crop traits. Appl Plant Sci 7:e1211. https://doi.org/10.1002/aps3.1211

Purty RS, Kumar G, Singla-Pareek SL, Pareek A (2008) Towards salinity tolerance in Brassica: an overview. Physiol Mol Biol Plants 14:39-49. https://doi.org/10.1007/s12298-008-0004-4

Qin J, Dong WY, He KN, Yu Y, Tan GD, Han L, Dong M, Zhang YY, Zhang D, Li, AZ, Wang ZI (2010) NaCl salinity-induced changes in water status, ion contents and photosynthetic properties of Shepherdia argentea (Pursh) Nutt. seedlings. Plant Soil Environ 56:325-332. https://doi.org/10.17221/209/2009-PSE

R Core Team (2020) R: A language and environment for statistical computing. R Foundation for Statistical Computing, Vienna, Austria.

Radanielson AM, Gaydon DS, Li T, Angeles O, Roth CH (2018) Modeling salinity effect on rice growth and grain yield with ORYZA v3 and APSIM-Oryza. Eur J Agron 100:44-55. https://doi.org/10.1016/j.eja.2018.01.015

Rajabi Dehnavi A, Zahedi M, Ludwiczak A, Perez SC, Piernik A (2020) Effect of salinity on seed germination and seedling development of sorghum (Sorghum bicolor (L.) Moench) genotypes. Agronomy 10:859. https://doi.org/10.3390/agronomy10060859

Rajeswari S, Sood N, Swarup TG, Subramanian R (2019) Assessing salt-stress tolerance in barley. Univ Scie 24:91https://doi.org/109. 10.11144/Javeriana.SC24-1.asst 
Rasel M, Tahjib-Ul-Arif M, Hossain MA, Hassan L, Farzana S, Brestic M (2020) Screening of salt-tolerant rice landraces by seedling stage phenotyping and dissecting biochemical determinants of tolerance mechanism. $\mathrm{J}$ Plant Growth Regul 7:1-16. https://doi.org/10.1007/s00344-020-10235-9

Ryu JY, Lee HJ, Seo PJ, Jung JH, Ahn JH, Park CM (2014) The Arabidopsis floral repressor BFT delaysflowering by competing with FT for FD binding under high salinity. Mol Plant 7:377-387. https://doi.org/10.1093/mp/sst114

Saeed Z, Naveed M, Imran M, Bashir MA, Sattar A, Mustafa A, Hussain A, Xu M (2019) Combined use of Enterobacter sp. MN17 and zeolite reverts the adverse effects of cadmium on growth, physiology and antioxidant activity of Brassica napus. PLoS ONE 14:e0213016. https://doi.org/10.1371/journal.pone.0213016

Sairam RK, Veerabhadra R, Srivastava GC (2002) Differential response of wheat genotypes to long term salinity stress in relation to oxidative stress, antioxidant activity and osmolyte concentration. Plant Sci 163:10371046. https://doi.org/10.1016/S0168-9452(02)00278-9

Saqib M, Zorb C, Rengel Z, Schubert S (2005) The expression of the endogenous vacuolar $\mathrm{Na}^{+} / \mathrm{H}^{+}$antiporters in roots and shoots correlates positively with the salt resistance of wheat (Triticum aestivum L.). Plant Sci 169:959965. https://doi.org/10.1016/j.plantsci.2005.07.001

SAS (2011) Base SAS 9.1 procedures guide. SAS Institute Inc, Cary

Shabala S, Cuin TA (2003) Potassium transport and plant salt tolerance. Physiol Plant 133:651-669. https://doi.org/10.1111/j.1399-3054.2007.01008.x

Shah SH, Houborg R, McCabe MF (2020) Response of chlorophyll, carotenoid and spad-502 measurement to salinity and nutrient stress in wheat (Triticum aestivum L.). Agronomy 7:61. https://doi.org/10.3390/agronomy7030061

Shin YK, Bhandari SR, Jo JS, Song JW, Cho MC, Yang EY, Lee JG (2020) Response to salt stress in lettuce: changes in chlorophyll fluorescence parameters, phytochemical contents, and antioxidant activities. Agronomy 10:1627. https://doi.org/10.3390/agronomy 10111627

Singh P, Mahajan MM, Singh NK, Kumar D, Kumar K (2020) Physiological and molecular response under salinity stress in bread wheat (Triticum aestivum L.). J Plant Biochem Biot 29: 125-133. https://doi.org/10.1007/s13562-019-00521-3

Smith HF (1936) A discriminant function for plant selection. Ann. Eugen.7: 240-250. http://dx.doi.org/10.1111/j.1469-1809.1936.tb02143.x

Sohan D, Jasoni R, Zajicek J (1999) Plant-water relation of $\mathrm{NaCl}$ and calcium treated sunflowers plants. Envi Experi Bot 42:105-111. https://doi.org/10.1016/S0098-8472(99)00027-1

Tavakkoli E, Rengasamy P, Glenn K, McDonald K (2011) The response of barley to salinity stress differs between hydroponic and soil system. Funct Plant Biol 37:621-633. https://doi.org/10.1071/FP09202

Vaezi B, Pour-Aboughadareh A, Mehraban A, Hossein-Pour T, Mohammadi R, Armion M, Dorri M (2018) The use of parametric and non-parametric measures for selecting stable and adapted barley lines. Arch Agron Soil Sci 64:597-611. https://doi.org/10.1080/03650340.2017.1369529 
Vaezi B, Pour-Aboughadareh A, Mohammadi R, Armion M, Mehraban A, Hossein-Pour T, Dorii M (2017) GGE biplot and AMMI analysis of barley yield performance in Iran. Cereal Res Commun 45: 500-511. https://doi.org/10.1556/0806.45.2017.019

Vaezi B, Pour-Aboughadareh A, Mohammadi R, Mehraban A, Hossein-Pour T, Koohkan E, Ghasemi S, Moradkhani H, Siddique KH (2019) Integrating different stability models to investigate genotype xenvironment interactions and identify stable and high-yielding barley genotypes. Euphytica 215:63. https://doi.org/10.1007/s10681-019-2386-5

Williams JS (1962) The evaluation of a selection index. Biometrics18: 375-393. http://dx.doi.org/10.2307/2527479

Yang Y, Costa A, Leonhardt N, Siegel RS, Schroeder JI (2008) Isolation of a strong Arabidopsis guard cell promoter and its potential as a research tool. Plant Methods 4:6. https://doi.org/10.1186/1746-4811-4-6

Zobel RW, Wright MJ, Gauch HG (1998) Statistical analysis of yield trials. Agron J 80:388-393. https://doi.org/10.2134/agronj1988.00021962008000030002x

Zuffo A, Steiner F, Aguilera JG, Teodoro PE, Teodoro LPR, Busch A (2021) Multi-trait stability index: A tool for simultaneous selection of soya bean genotypes in drought and saline stress. Journal of Agronomy and Crop Science 207:163-169. https://doi.org/10.1111/jac.12439 
Table 1 Combined analysis of variance of the measured traits in 20 barley genotypes under control and salinity stress conditions

\begin{tabular}{|c|c|c|c|c|c|}
\hline Trait & $\begin{array}{l}\text { Salinity treatment } \\
(\mathrm{S} ; d f=1)\end{array}$ & $\begin{array}{l}\text { Replication / S } \\
(d f=4)\end{array}$ & $\begin{array}{l}\text { Genotype } \\
(\mathrm{G} ; d f=19)\end{array}$ & $\begin{array}{l}\mathrm{S} \times \mathrm{G} \\
(d f=19)\end{array}$ & $\begin{array}{l}\text { Error } \\
(d f=76)\end{array}$ \\
\hline Root fresh weight (RFW) & $108.39^{* * * *}$ & 1.09 & $1.6^{* *}$ & 1.05 & 0.66 \\
\hline Shoot fresh weight (SFW) & $5898.39^{* * *}$ & 35.17 & $49.63^{* *}$ & $23.98^{*}$ & 11.61 \\
\hline Root dry weight (RDW) & $0.47^{* *}$ & 0.02 & 0.01 & 0.005 & 0.007 \\
\hline Shoot dry weight (SDW) & $64.64^{* *}$ & 1.85 & $0.51^{*}$ & 0.27 & 0.3 \\
\hline Membrane stability index (MSI) & $9242.18^{*}$ & 776.24 & $405.6^{* * *}$ & 206.04 & 130.21 \\
\hline Relative water content (RWC) & $6276.623^{* *}$ & 285.07 & $117.9^{* *}$ & $136.07^{* *}$ & 53.17 \\
\hline Relative chlorophyll content (SPAD) & $590.96^{*}$ & 42.77 & $28.06^{* *}$ & 19.35 & 15.3 \\
\hline Photosynthetic rate $\left(\mathrm{P}_{\mathrm{N}}\right)$ & 110.68 & 64.71 & 37.74 & 30.49 & 23.63 \\
\hline Stomatal conductance $\left(G_{S}\right)$ & $7731.02^{*}$ & 620.89 & 213.54 & 251.32 & 222.22 \\
\hline Transpiration rate $\left(T_{E}\right)$ & $13.35^{* * *}$ & 0.01 & $0.33^{* *}$ & $0.39^{* *}$ & 0.14 \\
\hline Root $\mathrm{Na}^{+}$content $(\mathrm{RN})$ & $403186^{* * *}$ & 2996.48 & $6373.21^{* * *}$ & $12485.03^{* * *}$ & 1592.84 \\
\hline Shoot $\mathrm{Na}^{+}$content $(\mathrm{SN})$ & $331272.10^{* * * *}$ & 165.4 & $1691.4^{* * *}$ & $1741.66^{* * *}$ & 134.16 \\
\hline Root $\mathrm{K}^{+}$content $(\mathrm{RK})$ & $2354.89^{* * *}$ & 4.1 & $10.37^{* * *}$ & $8.19^{* * *}$ & 1.81 \\
\hline Shoot $\mathrm{Na}^{+}$content $(\mathrm{SN})$ & $1079.4^{* * *}$ & 4.06 & $23.76^{* * *}$ & $21.80^{* * *}$ & 4.18 \\
\hline Root $\mathrm{K}+/ \mathrm{Na}+$ ratio $(\mathrm{RKN})$ & $0.26^{* * *}$ & 0.0001 & $0.003^{* * *}$ & $0.003^{* * *}$ & 0.001 \\
\hline Shoot $\mathrm{K}+/ \mathrm{Na}+$ ratio $(\mathrm{SKN})$ & $35.32^{* * *}$ & 0.11 & $0.24^{* * *}$ & $0.24^{* * *}$ & 0.06 \\
\hline Root-to-shoot $\mathrm{Na}^{+}$translocation (RTSN) & $5.23^{* * *}$ & 0.04 & $0.08^{* * *}$ & $0.10^{* * *}$ & 0.01 \\
\hline Root-to-shoot $\mathrm{K}^{+}$translocation (RTSK) & $2802.18^{* *}$ & 51.77 & $43.53^{*}$ & $44.56^{*}$ & 22.87 \\
\hline
\end{tabular}

$*, p<0.05 ; * *, p<0.01 ; * * *, p<0.001$. 
Table 2 Performance and percent reduction of barley genotypes considering root and shoot growth features, water relative content, and membrane stability index at the seedling stage under control and salinity conditions

\begin{tabular}{|c|c|c|c|c|c|c|c|c|c|c|c|c|c|c|c|c|c|c|}
\hline \multirow{2}{*}{$\begin{array}{l}\text { Genotype } \\
\text { code }\end{array}$} & \multicolumn{3}{|c|}{ RFW } & \multicolumn{3}{|c|}{ RDW } & \multicolumn{3}{|l|}{ SFW } & \multicolumn{3}{|c|}{ SDW } & \multicolumn{3}{|l|}{ RWC } & \multicolumn{3}{|l|}{ MSI } \\
\hline & $\mathrm{C}$ & $\mathrm{S}$ & $\mathrm{R} \%$ & $\mathrm{C}$ & $\mathrm{S}$ & $\mathrm{R} \%$ & $\mathrm{C}$ & $\mathrm{S}$ & $\mathrm{R} \%$ & $\mathrm{C}$ & $\mathrm{S}$ & $\mathrm{R} \%$ & $\mathrm{C}$ & $\mathrm{S}$ & $\mathrm{R} \%$ & $\mathrm{C}$ & $\mathrm{S}$ & $\mathrm{R} \%$ \\
\hline G1 & 3.08 & 1.65 & 46.49 & 0.27 & 0.12 & 53.32 & 19.03 & 3.55 & 81.35 & 2.88 & 0.83 & 71.33 & 89.60 & 84.88 & 5.26 & 92.03 & 78.72 & 14.46 \\
\hline G2 & 4.58 & 1.37 & 70.13 & 0.31 & 0.20 & 35.95 & 24.17 & 7.63 & 68.41 & 2.97 & 1.26 & 57.62 & 95.16 & 77.33 & 18.74 & 73.76 & 37.66 & 48.94 \\
\hline G3 & 3.48 & 0.90 & 74.10 & 0.15 & 0.10 & 32.03 & 24.39 & 6.63 & 72.80 & 2.05 & 1.04 & 49.04 & 93.34 & 62.37 & 33.18 & 87.90 & 80.46 & 8.46 \\
\hline G4 & 4.13 & 1.35 & 67.34 & 0.30 & 0.13 & 57.28 & 11.90 & 4.55 & 61.76 & 2.30 & 1.34 & 41.82 & 94.46 & 63.95 & 32.30 & 92.53 & 79.36 & 14.24 \\
\hline G5 & 3.43 & 1.10 & 67.96 & 0.30 & 0.13 & 58.14 & 17.20 & 4.17 & 75.78 & 2.56 & 0.87 & 65.91 & 95.18 & 69.95 & 26.51 & 92.89 & 93.36 & -0.51 \\
\hline G6 & 3.80 & 1.08 & 71.49 & 0.30 & 0.12 & 61.06 & 29.07 & 6.17 & 78.78 & 3.69 & 0.96 & 73.86 & 89.52 & 87.32 & 2.46 & 89.03 & 66.03 & 25.83 \\
\hline G7 & 2.60 & 1.27 & 51.28 & 0.22 & 0.14 & 36.82 & 14.20 & 7.05 & 50.35 & 2.01 & 1.07 & 46.57 & 93.97 & 80.06 & 14.81 & 89.85 & 77.47 & 13.78 \\
\hline G8 & 2.92 & 1.42 & 51.43 & 0.28 & 0.12 & 56.32 & 18.03 & 3.12 & 82.71 & 1.75 & 0.83 & 52.91 & 92.60 & 90.14 & 2.65 & 93.05 & 76.29 & 18.02 \\
\hline G9 & 2.90 & 1.53 & 47.13 & 0.31 & 0.16 & 50.34 & 23.72 & 4.95 & 79.13 & 2.76 & 1.01 & 63.38 & 86.93 & 76.94 & 11.50 & 92.60 & 74.89 & 19.12 \\
\hline G10 & 4.70 & 1.75 & 62.77 & 0.40 & 0.18 & 55.17 & 21.75 & 5.47 & 74.87 & 2.52 & 1.00 & 60.52 & 94.61 & 67.52 & 28.63 & 91.72 & 86.66 & 5.52 \\
\hline G11 & 1.92 & 1.08 & 43.48 & 0.18 & 0.12 & 35.81 & 19.43 & 4.33 & 77.69 & 2.39 & 0.99 & 58.40 & 96.77 & 81.47 & 15.81 & 91.05 & 77.98 & 14.36 \\
\hline G12 & 2.38 & 1.18 & 50.35 & 0.19 & 0.13 & 34.77 & 16.03 & 3.77 & 76.51 & 2.37 & 0.84 & 64.44 & 94.09 & 83.85 & 10.88 & 93.16 & 57.51 & 38.27 \\
\hline G13 & 3.27 & 0.95 & 70.92 & 0.30 & 0.11 & 64.57 & 16.42 & 3.60 & 78.07 & 2.44 & 0.82 & 66.58 & 96.99 & 72.01 & 25.76 & 88.83 & 57.96 & 34.75 \\
\hline G14 & 2.33 & 1.22 & 47.85 & 0.20 & 0.14 & 26.63 & 13.75 & 4.25 & 69.09 & 2.06 & 0.76 & 63.10 & 93.55 & 85.58 & 8.52 & 89.70 & 61.03 & 31.97 \\
\hline G15 & 1.60 & 0.87 & 45.83 & 0.22 & 0.10 & 53.20 & 9.63 & 1.98 & 79.48 & 1.84 & 0.67 & 63.59 & 88.31 & 84.10 & 4.77 & 91.08 & 75.98 & 16.58 \\
\hline G16 & 3.30 & 1.30 & 60.61 & 0.29 & 0.13 & 53.74 & 19.47 & 3.60 & 81.51 & 2.47 & 1.17 & 52.73 & 94.22 & 88.48 & 6.10 & 91.56 & 81.89 & 10.55 \\
\hline G17 & 2.60 & 0.63 & 75.64 & 0.24 & 0.07 & 70.60 & 16.67 & 2.40 & 85.60 & 2.31 & 0.55 & 76.02 & 88.61 & 72.21 & 18.51 & 89.76 & 72.56 & 19.16 \\
\hline G18 & 2.18 & 1.10 & 49.62 & 0.20 & 0.10 & 49.97 & 14.20 & 2.60 & 81.69 & 2.10 & 0.68 & 67.69 & 96.01 & 86.45 & 9.96 & 89.81 & 90.66 & -0.94 \\
\hline G19 & 4.38 & 0.93 & 78.67 & 0.25 & 0.11 & 56.07 & 17.50 & 2.33 & 86.71 & 1.92 & 0.66 & 65.94 & 92.79 & 70.19 & 24.36 & 92.60 & 51.98 & 43.86 \\
\hline G20 & 3.33 & 2.20 & 33.83 & 0.24 & 0.23 & 4.17 & 19.42 & 3.38 & 82.62 & 2.72 & 1.41 & 48.31 & 95.16 & 87.80 & 7.74 & 91.91 & 75.33 & 18.04 \\
\hline Means & 3.15 & 1.24 & 60.44 & 0.26 & 0.13 & 48.75 & 18.30 & 4.28 & 76.63 & 2.41 & 0.94 & 61.03 & 93.09 & 78.63 & 15.54 & 90.24 & 72.69 & 19.45 \\
\hline
\end{tabular}

RFW, root fresh weight $\left(\mathrm{g}_{\text {plant }}^{-1}\right)$; RDW, root dry weight $\left(\mathrm{g} \mathrm{plant}^{-1}\right)$; SFW, shoot fresh weight $\left(\mathrm{g}\right.$ plant $\left.{ }^{-1}\right)$; SDW, shoot dry weight $\left(\mathrm{g}\right.$ plant $\left.{ }^{-1}\right)$; RWC, relative water content; MSI, membrane stability index.

$\mathrm{C}$, control conditions; S salinity stress conditions; R\%, percent reduction due to salinity stress compared to control conditions (negative numbers indicate value higher than control conditions) 


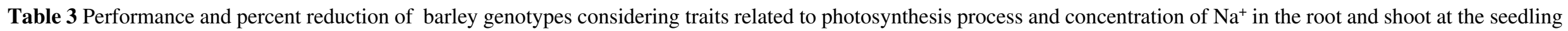
stage under control and salinity conditions

\begin{tabular}{|c|c|c|c|c|c|c|c|c|c|c|c|c|c|c|c|c|c|c|}
\hline \multirow{2}{*}{$\begin{array}{l}\text { Genotype } \\
\text { code }\end{array}$} & \multicolumn{3}{|l|}{ SPAD } & \multicolumn{3}{|l|}{$P_{N}$} & \multicolumn{3}{|l|}{$G_{S}$} & \multicolumn{3}{|l|}{$T_{E}$} & \multicolumn{3}{|l|}{$\mathrm{RN}$} & \multicolumn{3}{|l|}{$\mathrm{SN}$} \\
\hline & $\mathrm{C}$ & $\mathrm{S}$ & $\mathrm{R} \%$ & $\mathrm{C}$ & $\mathrm{S}$ & $\mathrm{R} \%$ & $\mathrm{C}$ & $\mathrm{S}$ & $\mathrm{R} \%$ & $\mathrm{C}$ & $\mathrm{S}$ & $\mathrm{R} \%$ & $\mathrm{C}$ & $\mathrm{S}$ & $\mathrm{R} \%$ & $\mathrm{C}$ & $\mathrm{S}$ & $\mathrm{R} \%$ \\
\hline G1 & 38.73 & 33.60 & 13.25 & 20.90 & 16.87 & 19.28 & 5.33 & 5.00 & 6.25 & 0.32 & 0.30 & 5.79 & 72.45 & 347.54 & -379.70 & 9.99 & 120.89 & -1110.11 \\
\hline G3 & 36.20 & 26.93 & 25.60 & 26.87 & 21.43 & 20.22 & 18.35 & 0.63 & 96.55 & 1.08 & 0.05 & 95.81 & 118.68 & 204.14 & -72.01 & 10.35 & 127.88 & -1135.95 \\
\hline G4 & 37.40 & 36.90 & 1.34 & 22.10 & 17.70 & 19.91 & 18.27 & 3.60 & 80.29 & 0.36 & 0.16 & 55.34 & 79.45 & 278.57 & -250.64 & 10.85 & 123.03 & -1034.26 \\
\hline G5 & 37.00 & 38.30 & -3.51 & 21.80 & 18.03 & 17.28 & 34.33 & 0.97 & 97.18 & 0.48 & 0.07 & 85.82 & 121.73 & 177.50 & -45.81 & 10.84 & 108.80 & -903.38 \\
\hline G6 & 37.13 & 35.60 & 4.13 & 23.97 & 17.90 & 25.31 & 49.00 & 2.03 & 95.87 & 1.24 & 0.17 & 86.11 & 86.84 & 300.42 & -245.96 & 11.34 & 121.47 & -970.85 \\
\hline G7 & 38.63 & 30.30 & 21.57 & 28.73 & 24.57 & 14.50 & 44.33 & 4.30 & 90.30 & 1.45 & 0.23 & 83.76 & 116.06 & 309.30 & -166.50 & 12.63 & 129.57 & -926.16 \\
\hline G8 & 38.60 & 33.50 & 13.21 & 25.10 & 18.73 & 25.37 & 30.48 & 1.86 & 93.91 & 0.68 & 0.11 & 83.65 & 285.88 & 270.38 & 5.42 & 14.23 & 72.30 & -408.08 \\
\hline G9 & 35.37 & 27.67 & 21.77 & 20.90 & 15.05 & 27.99 & 14.60 & 1.95 & 86.64 & 1.59 & 0.08 & 94.91 & 74.67 & 241.78 & -223.78 & 18.03 & 105.70 & -486.35 \\
\hline G10 & 37.80 & 39.60 & -4.76 & 29.00 & 19.80 & 31.72 & 20.67 & 1.85 & 91.05 & 1.72 & 0.03 & 97.98 & 74.88 & 293.59 & -292.08 & 8.88 & 98.11 & -1004.43 \\
\hline G11 & 42.40 & 30.17 & 28.85 & 25.17 & 20.47 & 18.68 & 19.70 & 2.50 & 87.31 & 0.34 & 0.15 & 56.39 & 275.24 & 155.65 & 43.45 & 12.63 & 123.20 & -875.71 \\
\hline G12 & 36.10 & 34.33 & 4.89 & 21.43 & 20.13 & 6.07 & 7.93 & 4.76 & 40.00 & 0.44 & 0.26 & 41.59 & 133.26 & 245.11 & -83.93 & 14.55 & 155.94 & -971.51 \\
\hline G13 & 37.90 & 33.80 & 10.82 & 24.00 & 22.53 & 6.11 & 10.47 & 1.60 & 84.73 & 0.65 & 0.09 & 87.02 & 152.85 & 238.28 & -55.89 & 14.34 & 125.70 & -776.57 \\
\hline G14 & 42.07 & 34.97 & 16.88 & 24.40 & 23.67 & 2.99 & 15.97 & 3.55 & 77.77 & 0.88 & 0.18 & 79.29 & 103.15 & 261.49 & -153.50 & 9.78 & 112.27 & -1048.34 \\
\hline G15 & 37.97 & 36.93 & 2.72 & 29.15 & 20.50 & 29.67 & 20.47 & 3.00 & 85.34 & 1.13 & 0.17 & 85.25 & 90.54 & 215.52 & -138.03 & 7.99 & 59.84 & -648.63 \\
\hline G16 & 38.07 & 34.63 & 9.02 & 26.80 & 19.37 & 27.74 & 27.27 & 5.75 & 78.91 & 1.53 & 0.22 & 85.86 & 131.37 & 302.93 & -130.59 & 16.90 & 124.08 & -634.06 \\
\hline G17 & 38.50 & 33.90 & 11.95 & 21.93 & 19.83 & 9.57 & 13.07 & 2.00 & 84.69 & 0.89 & 0.14 & 84.21 & 110.57 & 179.55 & -62.39 & 10.49 & 122.96 & -1072.16 \\
\hline G18 & 42.97 & 36.03 & 16.14 & 25.20 & 23.57 & 6.48 & 8.50 & 6.49 & 23.65 & 0.37 & 0.36 & 3.35 & 100.62 & 234.18 & -132.74 & 11.70 & 102.05 & -772.22 \\
\hline G19 & 38.30 & 33.40 & 12.79 & 17.33 & 16.77 & 3.23 & 6.73 & 2.33 & 65.35 & 0.34 & 0.15 & 55.92 & 147.03 & 241.01 & -63.92 & 18.72 & 128.59 & -586.91 \\
\hline G20 & 33.60 & 31.07 & 7.54 & 24.25 & 23.10 & 4.74 & 8.15 & 2.77 & 66.04 & 0.64 & 0.10 & 84.13 & 148.76 & 166.58 & -11.98 & 7.99 & 220.03 & -2652.68 \\
\hline Mean & 38.20 & 33.77 & 11.62 & 23 & 21.08 & 8.35 & 19.35 & 3.30 & 82.96 & 0.82 & 0.15 & 81.19 & 126.45 & 242.38 & -91.68 & 12.30 & 117.38 & -854.56 \\
\hline
\end{tabular}

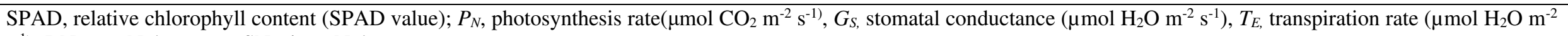
$\mathrm{s}^{-1}$ ); RN, root $\mathrm{Na}^{+}$content; $\mathrm{SN}$, shoot $\mathrm{Na}^{+}$content

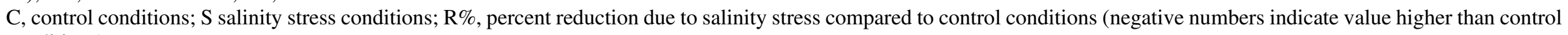
conditions) 


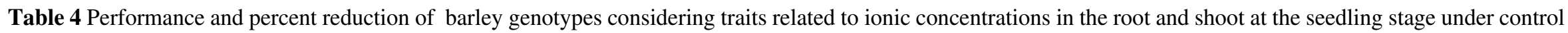
and salinity conditions

\begin{tabular}{|c|c|c|c|c|c|c|c|c|c|c|c|c|c|c|c|c|c|c|}
\hline \multirow{2}{*}{$\begin{array}{l}\text { Genotype } \\
\text { code }\end{array}$} & \multicolumn{3}{|l|}{ RK } & \multicolumn{3}{|l|}{ SK } & \multicolumn{3}{|c|}{ RKN } & \multicolumn{3}{|l|}{ SKN } & \multicolumn{3}{|c|}{ RTSN } & \multicolumn{3}{|c|}{ RTSK } \\
\hline & $\mathrm{C}$ & $\mathrm{S}$ & $\mathrm{R} \%$ & $\mathrm{C}$ & $\mathrm{S}$ & $\mathrm{R} \%$ & $\mathrm{C}$ & $\mathrm{S}$ & $\mathrm{R} \%$ & $\mathrm{C}$ & $\mathrm{S}$ & $\mathrm{R} \%$ & $\mathrm{C}$ & $\mathrm{S}$ & $\mathrm{R} \%$ & $\mathrm{C}$ & $\mathrm{S}$ & $\mathrm{R} \%$ \\
\hline G1 & 10.67 & 0.60 & 94.38 & 14.87 & 6.24 & 58.03 & 0.15 & 0.002 & 98.86 & 1.48 & 0.06 & 96.18 & 0.15 & 0.35 & -131.54 & 1.48 & 12.59 & -752.145 \\
\hline G2 & 9.19 & 0.66 & 92.82 & 13.92 & 3.70 & 73.45 & 0.09 & 0.004 & 95.89 & 1.12 & 0.06 & 94.94 & 0.14 & 0.37 & -162.86 & 1.54 & 10.24 & -564.439 \\
\hline G3 & 14.90 & 1.15 & 92.30 & 12.73 & 5.35 & 57.95 & 0.13 & 0.016 & 95.30 & 1.29 & 0.04 & 96.65 & 0.09 & 0.69 & -689.31 & 0.86 & 4.63 & -438.872 \\
\hline G4 & 14.01 & 1.49 & 89.34 & 13.42 & 5.28 & 60.62 & 0.19 & 0.015 & 97.20 & 1.26 & 0.04 & 96.83 & 0.14 & 0.44 & -208.34 & 0.96 & 7.63 & -694.302 \\
\hline G5 & 8.73 & 0.64 & 92.63 & 14.23 & 7.88 & 44.61 & 0.09 & 0.004 & 95.47 & 1.57 & 0.07 & 95.34 & 0.13 & 0.66 & -425.84 & 1.64 & 17.36 & -958.981 \\
\hline G6 & 13.48 & 0.87 & 93.52 & 16.16 & 5.89 & 63.55 & 0.17 & 0.003 & 98.24 & 1.48 & 0.05 & 96.84 & 0.14 & 0.41 & -192.21 & 1.24 & 13.20 & -964.355 \\
\hline G7 & 11.08 & 0.71 & 93.59 & 3.42 & 5.33 & -55.75 & 0.11 & 0.002 & 97.82 & 0.30 & 0.05 & 84.60 & 0.14 & 0.44 & -227.71 & 0.33 & 7.27 & -2124.16 \\
\hline G8 & 5.60 & 0.69 & 87.61 & 15.86 & 7.08 & 55.35 & 0.02 & 0.003 & 86.29 & 1.13 & 0.10 & 91.12 & 0.05 & 0.27 & -437.83 & 2.84 & 10.20 & -259.127 \\
\hline G9 & 12.16 & 0.84 & 93.09 & 16.77 & 7.51 & 55.23 & 0.17 & 0.004 & 97.83 & 1.05 & 0.07 & 93.31 & 0.25 & 0.47 & -92.45 & 1.41 & 9.36 & -562.607 \\
\hline G10 & 9.70 & 1.02 & 89.49 & 13.42 & 6.50 & 51.56 & 0.14 & 0.004 & 97.30 & 1.48 & 0.07 & 95.49 & 0.13 & 0.33 & -149.25 & 1.48 & 6.98 & -372.464 \\
\hline G11 & 6.64 & 0.59 & 91.16 & 7.54 & 6.78 & 10.04 & 0.02 & 0.004 & 84.77 & 0.62 & 0.06 & 90.90 & 0.05 & 0.82 & -1689.28 & 1.13 & 12.41 & -997.789 \\
\hline G12 & 8.93 & 1.78 & 80.07 & 16.47 & 8.56 & 48.03 & 0.07 & 0.01 & 89.06 & 1.18 & 0.05 & 95.48 & 0.11 & 0.64 & -476.34 & 1.92 & 5.11 & -166.632 \\
\hline G13 & 7.99 & 0.75 & 90.65 & 12.24 & 7.70 & 37.14 & 0.05 & 0.003 & 94.44 & 0.86 & 0.06 & 93.02 & 0.10 & 0.54 & -463.23 & 1.52 & 14.06 & -824.229 \\
\hline G14 & 9.11 & 0.91 & 89.98 & 12.50 & 7.67 & 38.61 & 0.09 & 0.004 & 95.80 & 1.37 & 0.07 & 95.13 & 0.10 & 0.43 & -348.96 & 1.37 & 10.55 & -667.372 \\
\hline G15 & 7.36 & 0.62 & 91.57 & 11.43 & 5.01 & 56.14 & 0.08 & 0.003 & 96.31 & 1.50 & 0.08 & 94.45 & 0.09 & 0.28 & -220.97 & 1.72 & 8.41 & -388.232 \\
\hline G16 & 7.20 & 0.71 & 90.09 & 13.87 & 5.77 & 58.43 & 0.06 & 0.002 & 95.82 & 0.83 & 0.04 & 94.78 & 0.13 & 0.42 & -229.68 & 1.96 & 9.75 & -398.019 \\
\hline G17 & 8.00 & 0.35 & 95.63 & 10.46 & 9.35 & 10.61 & 0.08 & 0.002 & 97.17 & 0.99 & 0.08 & 91.95 & 0.12 & 0.77 & -558.38 & 1.31 & 28.69 & -2094.08 \\
\hline G18 & 10.08 & 0.49 & 95.14 & 5.93 & 8.37 & -41.07 & 0.10 & 0.002 & 97.73 & 0.57 & 0.08 & 86.05 & 0.12 & 0.46 & -280.25 & 0.63 & 16.96 & -2592.27 \\
\hline G19 & 9.26 & 0.84 & 90.89 & 15.32 & 6.12 & 60.08 & 0.07 & 0.003 & 95.10 & 0.82 & 0.05 & 94.28 & 0.14 & 0.58 & -325.20 & 1.66 & 8.71 & -425.672 \\
\hline G20 & 10.14 & 1.31 & 87.04 & 15.25 & 9.76 & 36.00 & 0.07 & 0.01 & 88.36 & 2.00 & 0.04 & 97.84 & 0.06 & 1.33 & -2227.57 & 1.54 & 7.72 & -400.791 \\
\hline Mean & 9.71 & 0.85 & 91.23 & 12.79 & 6.79 & 46.89 & 0.10 & 0.004 & 96.11 & 1.15 & 0.06 & 94.70 & 0.12 & 0.53 & -356.27 & 1.43 & 11.09 & -677.46 \\
\hline
\end{tabular}

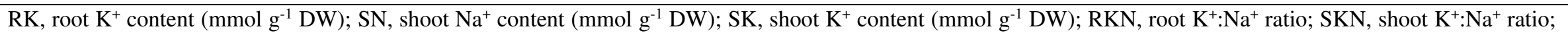
RTSN, root-to-shoot $\mathrm{Na}^{+}$translocation; RTKN, root-to-shoot $\mathrm{K}^{+}$translocation

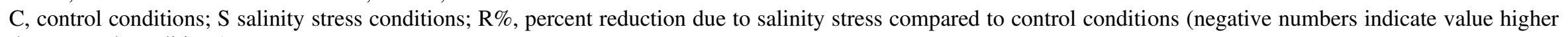
than control conditions) 
Table 5 Predicted genetic gain for the effective traits in the MGIDI index under salinity stress conditions

\begin{tabular}{lllll}
\hline Factor & Trait & Goal & $h^{2}$ & Selection gain $(\%)$ \\
\hline FA1 & Root $\mathrm{K}^{+}$content & Increase & 0.56 & 8.12 \\
FA1 & Root $\mathrm{K}^{+}: \mathrm{Na}^{+}$ratio & Increase & 0.65 & 3.08 \\
FA1 & Shoot $\mathrm{Na}^{+}$content & Decrease & 0.93 & 9.06 \\
FA1 & Root-to-shoot $\mathrm{Na}^{+}$translocation & Decrease & 0.87 & -7.81 \\
FA2 & Membrane stability index & Increase & 0.63 & -2.81 \\
FA2 & Shoot fresh weight & Increase & 0.77 & 0.64 \\
FA2 & Shoot $\mathrm{K}^{+}$content & Increase & 0.61 & 0.03 \\
FA3 & Relative water content & Increase & 0.63 & 2.23 \\
FA3 & Stomatal conductance & Increase & 0.61 & 0.15 \\
FA4 & Root $\mathrm{Na}^{+}$content & Decrease & 0.73 & 19.60 \\
\hline Total (Increase) & & & 42.91 \\
Total (Decrease) & & & -10.62 \\
\hline
\end{tabular}


Table 6 AMMI analysis of variance for grain yield of the 20 investigated barley genotypes

\begin{tabular}{llllll}
\hline Source of variation & $d f$ & MS & F-value & $(\mathrm{G}+\mathrm{E}+\mathrm{GE}) \%$ & $\mathrm{GE} \%$ \\
\hline Environment (E) & 4 & 24.31 & $23.12^{* * *}$ & 26 & \\
Replication / (E) & 10 & 1.05 & $3.45^{* * *}$ & 12 & \\
Genotype (G) & 19 & 2.27 & $7.44^{* * *}$ & 22 & \\
GE & 76 & 1.08 & $3.52^{* * *}$ & & 41.3 \\
PC1 & 22 & 1.53 & $5.03^{* * *}$ & 41.3 & 73.6 \\
PC2 & 20 & 1.32 & $4.31^{* * *}$ & 32.2 & 90.9 \\
PC3 & 18 & 0.79 & $2.58^{* * *}$ & 17.3 & 100 \\
PC4 & 16 & 0.66 & $1.52^{\text {ns }}$ & 9.1 & \\
Residuals & 190 & 0.31 & & & ESF1 \\
\hline Environment & YZD1 & YZD2 & BRJ1 & BRJ2 & $4.40(0.013)$ \\
\cline { 2 - 5 } Mean GY $( \pm \mathrm{SD})$ & 3.48 & 3.24 & 4.30 & $4.73(0.12)$ & $(0.09)$ \\
\end{tabular}

ns, non-significant; $* * *, p<0.001$.

YZD1, Yazd location (2018-2019); YZD2, Yazd location (2019-2020); BRJ1, Birjand location (2018-2019); BRJ2, Birjand location (2019-2020); ESF1, Esfahan location (2018-2019) 
Table 7 Mean grain yield $\left(\mathrm{t} \mathrm{ha}^{-1}\right)$ and several stability statistics of the 20 investigated barley genotypes across three saline regions of Iran

\begin{tabular}{|c|c|c|c|c|c|c|c|c|c|c|c|}
\hline \multirow{2}{*}{$\begin{array}{l}\text { Genotype } \\
\text { code }\end{array}$} & \multicolumn{6}{|c|}{ Grain yield $\left(\mathrm{t} \mathrm{ha}^{-1}\right)$} & \multicolumn{5}{|c|}{ Stability statistics } \\
\hline & BRJ1 & BRJ2 & ESF1 & YZD1 & YZD2 & Mean & $A S V$ & $E V$ & $S P I C$ & $Z a$ & $W A A S B$ \\
\hline G1 & 4.68 & 3.62 & 5.31 & 4.21 & 3.23 & 4.21 & 1.11 & 0.0755 & 0.96 & 0.212 & 0.423 \\
\hline G3 & 4.01 & 3.18 & 4.41 & 2.71 & 2.91 & 3.44 & 0.71 & 0.041 & 0.91 & 0.172 & 0.333 \\
\hline G4 & 4.41 & 4.29 & 5.23 & 3.48 & 3.73 & 4.23 & 0.56 & 0.022 & 0.66 & 0.137 & 0.269 \\
\hline G5 & 4.77 & 4.08 & 5.10 & 3.50 & 3.11 & 4.11 & 0.65 & 0.043 & 0.94 & 0.172 & 0.329 \\
\hline G6 & 3.77 & 5.61 & 5.52 & 4.43 & 4.22 & 4.71 & 0.38 & 0.115 & 1.2 & 0.168 & 0.294 \\
\hline G7 & 4.38 & 5.16 & 4.00 & 3.56 & 3.28 & 4.07 & 0.39 & 0.011 & 0.47 & 0.097 & 0.191 \\
\hline G8 & 4.21 & 4.58 & 4.17 & 3.48 & 2.81 & 3.85 & 0.07 & 0.006 & 0.11 & 0.018 & 0.035 \\
\hline G9 & 4.14 & 3.95 & 2.30 & 2.93 & 2.95 & 3.26 & 0.9 & 0.085 & 1.27 & 0.24 & 0.459 \\
\hline G10 & 3.95 & 4.86 & 3.11 & 3.01 & 2.61 & 3.51 & 0.67 & 0.0318 & 0.79 & 0.164 & 0.324 \\
\hline G11 & 4.28 & 3.95 & 4.52 & 2.93 & 2.76 & 3.69 & 0.39 & 0.0257 & 0.74 & 0.128 & 0.241 \\
\hline G12 & 4.05 & 5.08 & 4.21 & 4.18 & 3.91 & 4.28 & 0.28 & 0.0487 & 0.87 & 0.133 & 0.238 \\
\hline G13 & 4.36 & 4.97 & 3.80 & 2.93 & 3.95 & 4.00 & 0.52 & 0.019 & 0.62 & 0.125 & 0.245 \\
\hline G14 & 4.60 & 5.18 & 5.27 & 3.50 & 3.07 & 4.32 & 0.38 & 0.0213 & 0.61 & 0.105 & 0.196 \\
\hline G15 & 4.14 & 5.48 & 5.05 & 3.84 & 3.56 & 4.42 & 0.33 & 0.0248 & 0.71 & 0.116 & 0.213 \\
\hline G16 & 4.29 & 4.75 & 4.63 & 3.97 & 2.99 & 4.13 & 0.19 & 0.005 & 0.31 & 0.053 & 0.1102 \\
\hline G17 & 3.83 & 5.50 & 4.99 & 2.35 & 2.47 & 3.83 & 0.96 & 0.101 & 1.44 & 0.266 & 0.506 \\
\hline G18 & 4.45 & 5.80 & 5.35 & 3.45 & 4.07 & 4.63 & 0.58 & 0.033 & 0.81 & 0.155 & 0.299 \\
\hline G19 & 4.96 & 4.62 & 3.28 & 2.71 & 2.48 & 3.61 & 0.56 & 0.109 & 1.43 & 0.23 & 0.421 \\
\hline G2 & 4.67 & 4.04 & 4.23 & 5.29 & 3.30 & 4.31 & 1.07 & 0.128 & 1.77 & 0.325 & 0.618 \\
\hline G20 & 3.99 & 5.73 & 3.56 & 3.16 & 3.31 & 3.95 & 0.95 & 0.058 & 0.96 & 0.198 & 0.391 \\
\hline
\end{tabular}

YZD1, Yazd location (2018-2019); YZD2, Yazd location (2019-2020); BRJ1, Birjand location (2018-2019); BRJ2, Birjand location (2019-2020); ESF1, Esfahan location (2018-2019).

$A S V$, additive main effects and multiplicative interaction stability value; $E V$, averages of the squared eigenvector values; SPIC, ums of the absolute value of the IPCA scores; $Z a$, absolute value of the relative contribution of interaction principal component axes to the interaction; WAASB, weighted average of absolute scores from the singular value decomposition of the matrix of best linear unbiased predictions for the genotype $\times$ environment interaction effects generated by an linear mixed effect model 

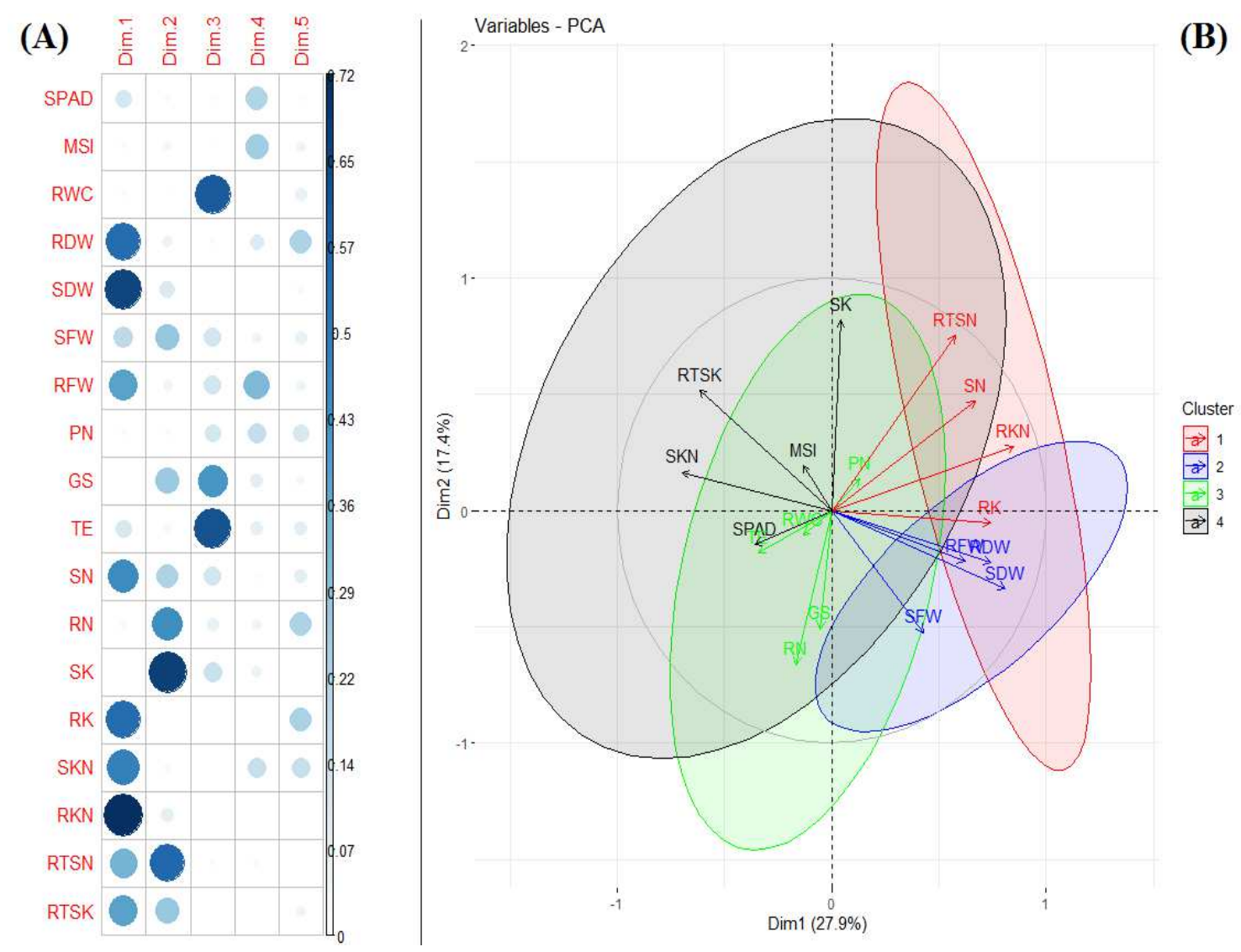

Figure 1 Principal component analysis (PCA) plot of various growth and physiological traits in the 20 investigated barley genotypes under salinity stress conditions. (A) The contribution of measured traits on extracted principal components based on square cosine and squared coordinates. (B) Grouping of the variables in the first two principal components. RFW, root fresh weight; SFW, shoot fresh weight; SDW, shoot dry weight; SPAD, relative chlorophyll content; $\mathrm{P}_{\mathrm{N}}$, photosynthetic rate; $\mathrm{G}_{\mathrm{S}}$, stomatal conductance; $\mathrm{T}_{\mathrm{E}}$, transpiration rate; MSI, membrane stability index; RWC, relative water content; $\mathrm{RN}$, root $\mathrm{Na}^{+}$content; $\mathrm{RK}$, root $\mathrm{K}^{+}$content; $\mathrm{SN}$, shoot $\mathrm{Na}^{+}$content; $\mathrm{SK}$, shoot $\mathrm{K}^{+}$content; $\mathrm{RKN}$, root $\mathrm{K}^{+}: \mathrm{Na}^{+}$ratio; SKN, shoot $\mathrm{K}^{+}: \mathrm{Na}^{+}$ratio; RTSN, root-to-shoot $\mathrm{Na}^{+}$translocation; RTKN, root-to-shoot $\mathrm{K}^{+}$ translocation. 


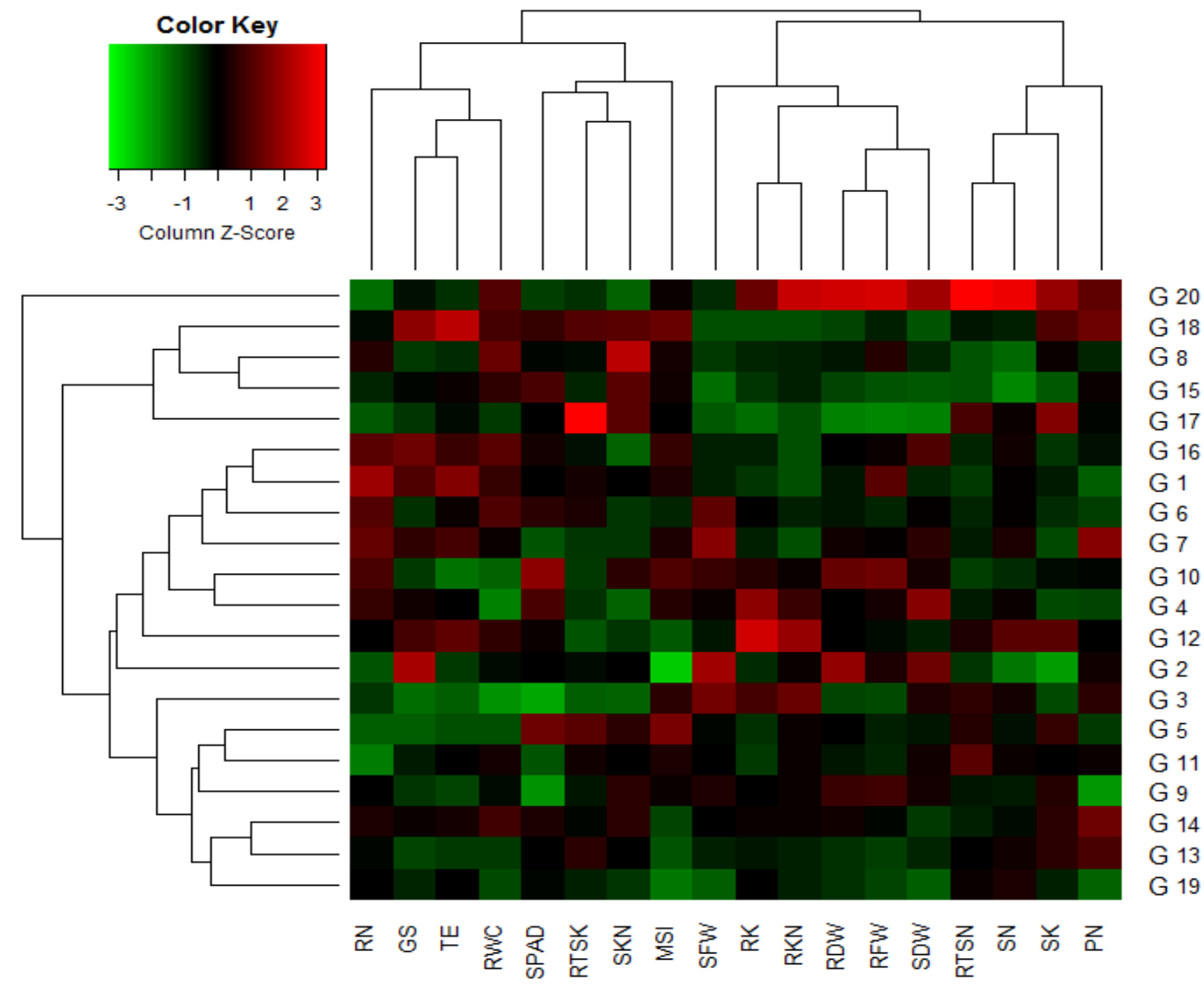

Figure 2 Graphical display of the relationships among in the 20 investigated barley genotypes and 18 measured growth and physiological traits under salinity stress conditions. The types of colors and color intensity were adjusted based on association among genotypes and traits. These colors are representative of a relative scale $(-3$ to +3$)$ derived after data standardization. The darker green indicates lower values, conversely the darker red indicates higher values. RFW, root fresh weight; SFW, shoot fresh weight; SDW, shoot dry weight; SPAD, relative chlorophyll content; $\mathrm{P}_{\mathrm{N}}$, photosynthetic rate; $\mathrm{G}_{\mathrm{S}}$, stomatal conductance; $\mathrm{T}_{\mathrm{E}}$, transpiration rate; MSI, membrane stability index; RWC, relative water content; $\mathrm{RN}$, root $\mathrm{Na}^{+}$content; $\mathrm{RK}$, root $\mathrm{K}^{+}$content; $\mathrm{SN}$, shoot $\mathrm{Na}^{+}$content; $\mathrm{SK}$, shoot $\mathrm{K}^{+}$content; $\mathrm{RKN}$, root $\mathrm{K}^{+}: \mathrm{Na}^{+}$ratio; $\mathrm{SKN}$, shoot $\mathrm{K}^{+}: \mathrm{Na}^{+}$ratio; RTSN, root-to-shoot $\mathrm{Na}^{+}$ translocation; RTKN, root-to-shoot $\mathrm{K}^{+}$translocation. 


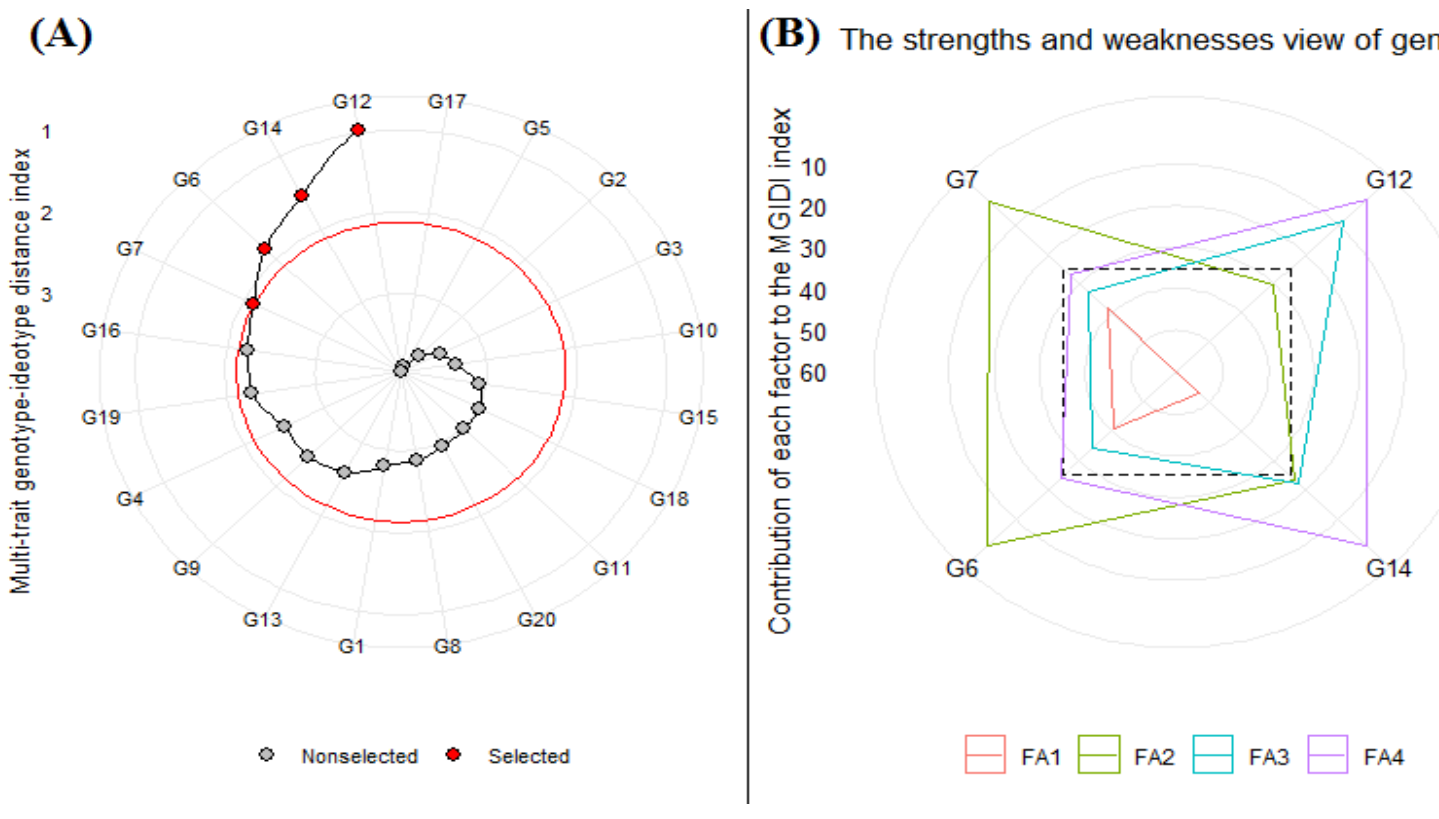

Figure 3 (A) Genotype ranking in ascending order for the MGIDI index. The selected genotypes based on this index are shown in red. The central red circle represents the cutpoint according to the selection pressure. (B) The strengths and weaknesses view of the selected genotypes is shown as the proportion of each factor on the computed MGIDI index. The smallest the proportion explained by a factor (closer to the external edge), the closer the traits within that factor are to the ideotype. The dashed line indicates the theoretical value if all the factors had contributed equally. 


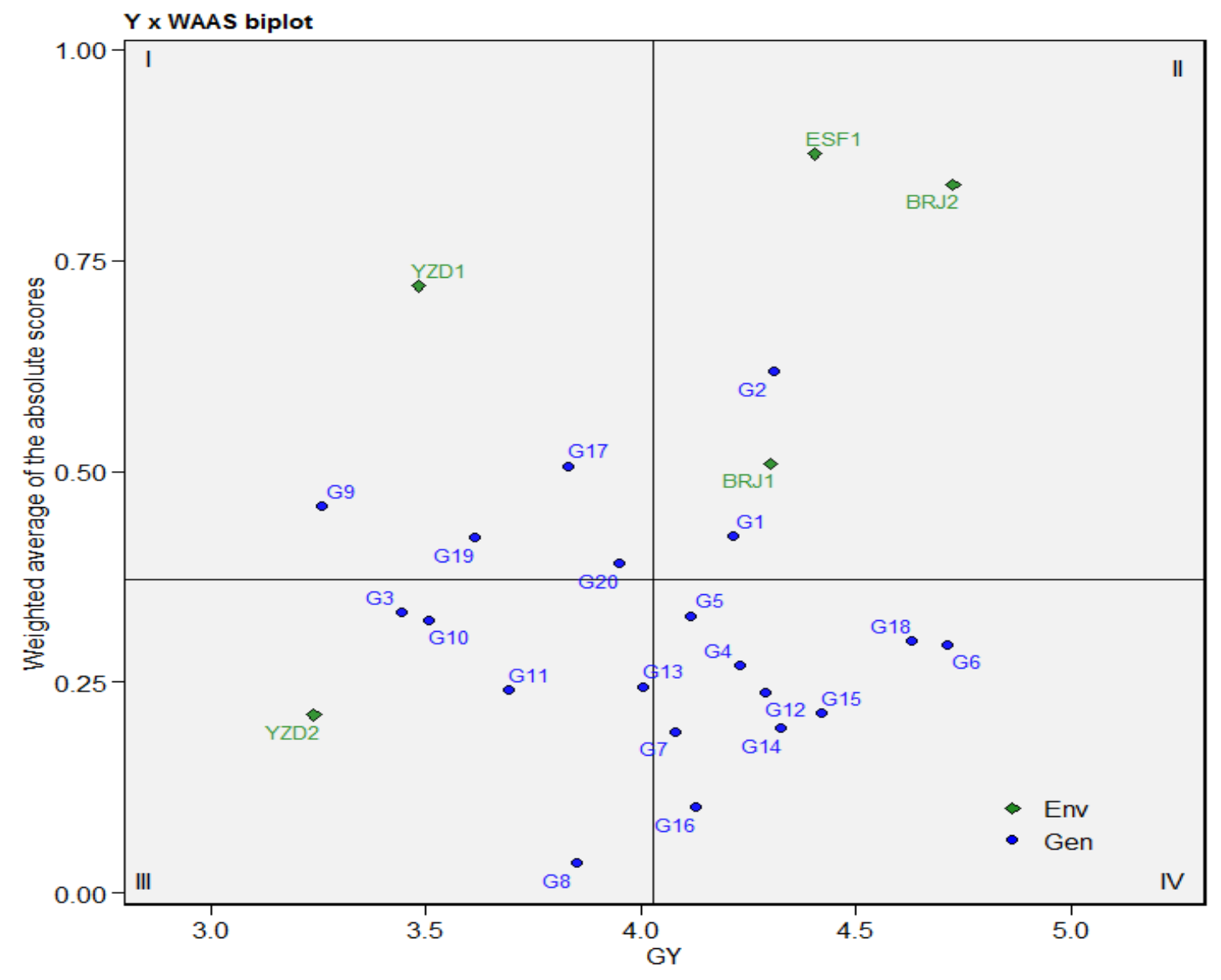

Figure 4 The WAASB $\times$ grain yield (GY) biplot for 20 barley genotypes in five environments. YZD1, Yazd location (2018-2019); YZD2, Yazd location (2019-2020); BRJ1, Birjand location (2018-2019); BRJ2, Birjand location (20192020); ESF1, Esfahan location (2018-2019). 


\section{Figures}
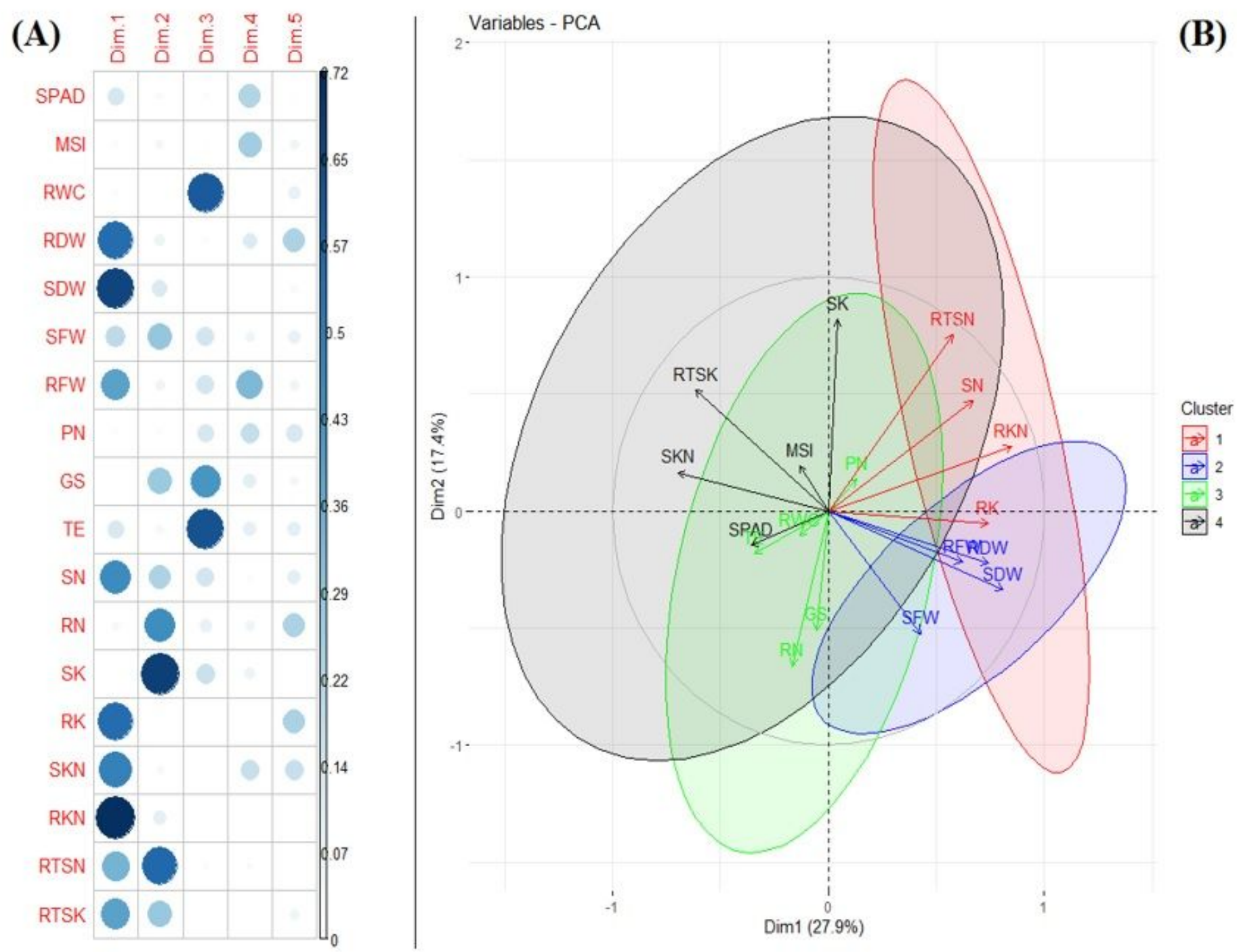

\section{Figure 1}

Principal component analysis (PCA) plot of various growth and physiological traits in the 20 investigated barley genotypes under salinity stress conditions. (A) The contribution of measured traits on extracted principal components based on square cosine and squared coordinates. (B) Grouping of the variables in the first two principal components. RFW, root fresh weight; SFW, shoot fresh weight; SDW, shoot dry weight; SPAD, relative chlorophyll content; PN, photosynthetic rate; GS, stomatal conductance; TE, transpiration rate; $\mathrm{MSI}$, membrane stability index; RWC, relative water content; RN, root $\mathrm{Na}+$ content; RK, root K+ content; $\mathrm{SN}$, shoot $\mathrm{Na}+$ content; $\mathrm{SK}$, shoot $\mathrm{K}+$ content; $\mathrm{RKN}$, root $\mathrm{K}+\mathrm{Na}+$ ratio; SKN, shoot $\mathrm{K}+\mathrm{Na}+$ ratio; RTSN, root-to-shoot Na+ translocation; RTKN, root-to-shoot $\mathrm{K}+$ translocation. 

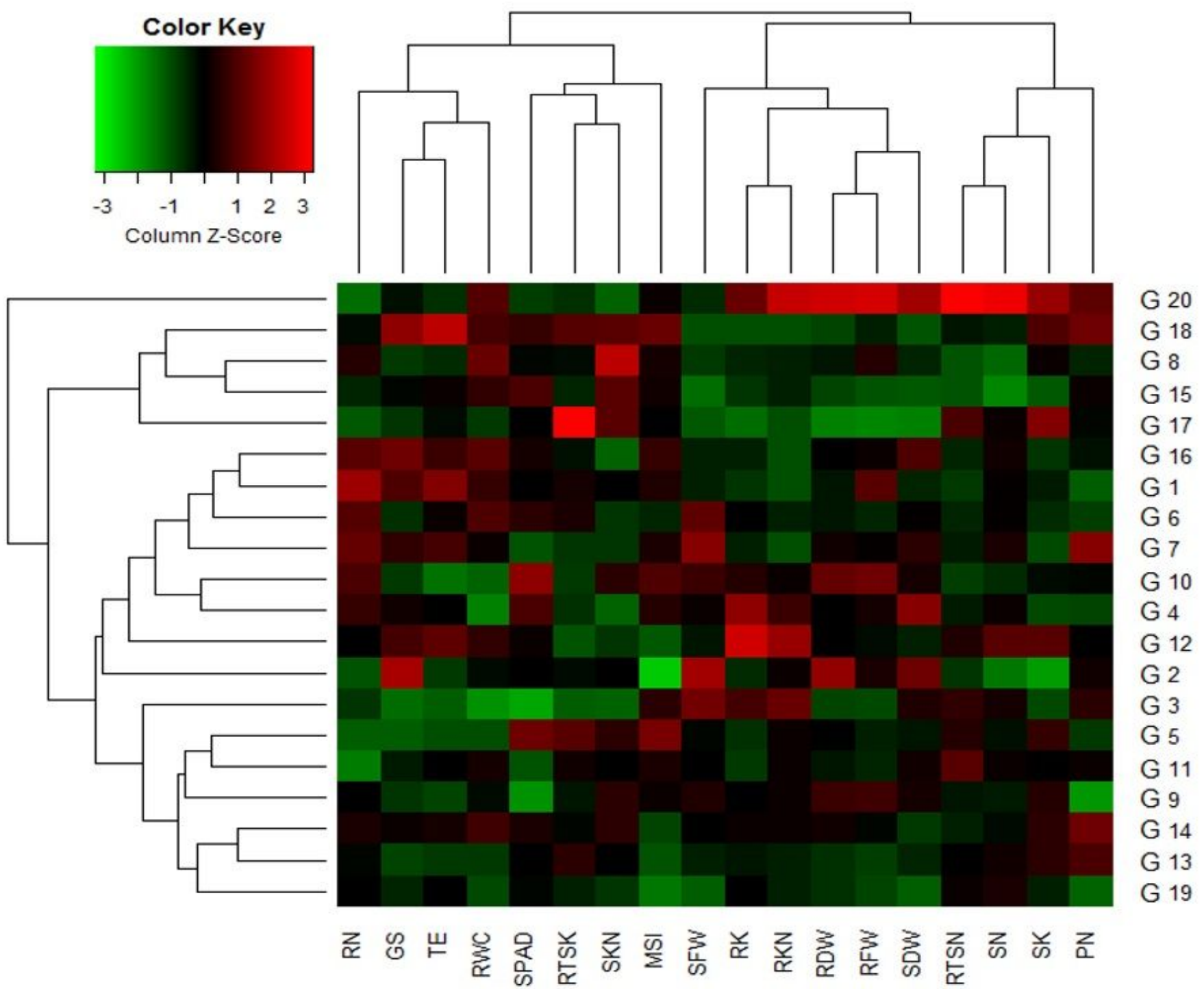

\section{Figure 2}

Graphical display of the relationships among in the 20 investigated barley genotypes and 18 measured growth and physiological traits under salinity stress conditions. The types of colors and color intensity were adjusted based on association among genotypes and traits. These colors are representative of a relative scale $(-3$ to +3$)$ derived after data standardization. The darker green indicates lower values, conversely the darker red indicates higher values. RFW, root fresh weight; SFW, shoot fresh weight; SDW, shoot dry weight; SPAD, relative chlorophyll content; PN, photosynthetic rate; GS, stomatal conductance; $\mathrm{TE}$, transpiration rate; $\mathrm{MSI}$, membrane stability index; RWC, relative water content; $\mathrm{RN}$, root $\mathrm{Na}$ + content; $\mathrm{RK}$, root $\mathrm{K}+$ content; $\mathrm{SN}$, shoot $\mathrm{Na}+$ content; $\mathrm{SK}$, shoot $\mathrm{K}+$ content; $\mathrm{RKN}$, root $\mathrm{K}+\mathrm{Na}+$ ratio; SKN, shoot $\mathrm{K}+\mathrm{Na}+$ ratio; RTSN, root-to-shoot $\mathrm{Na}+$ translocation; $\mathrm{RTKN}$, root-to-shoot $\mathrm{K}+$ translocation. 
(A)

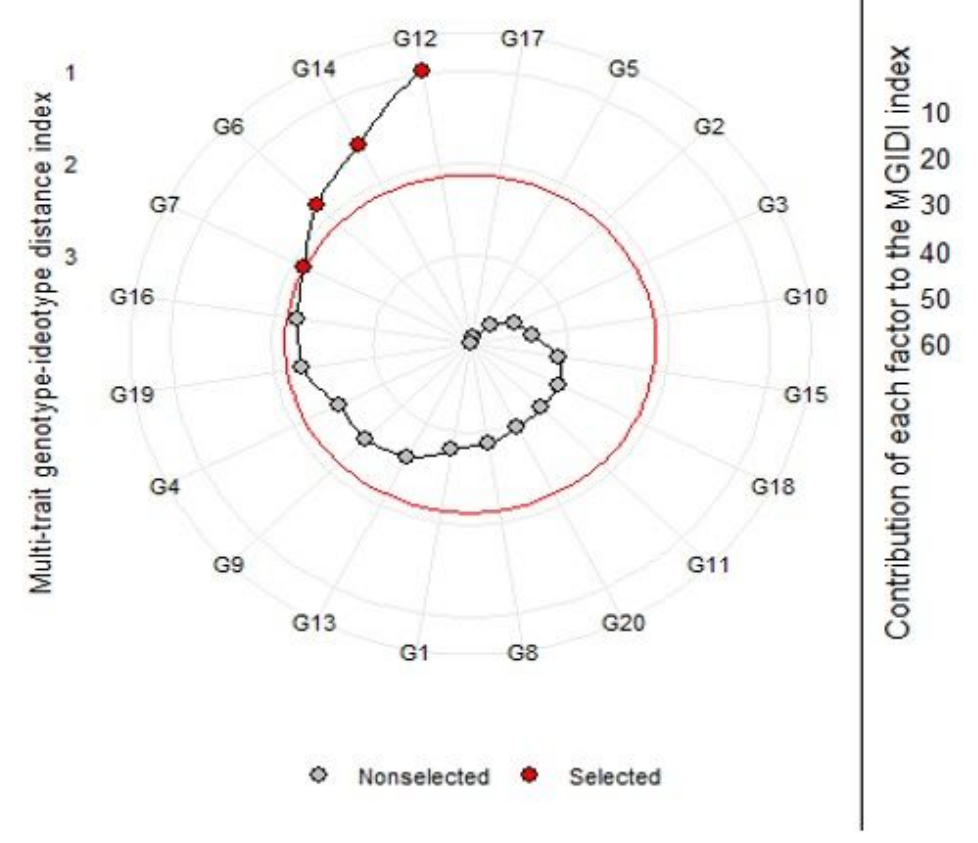

(B) The strengths and weaknesses view of genotypes

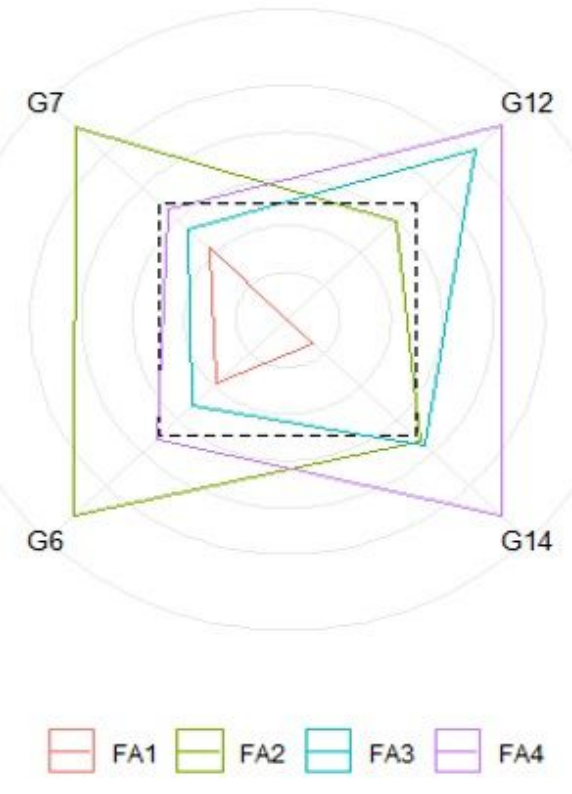

\section{Figure 3}

(A) Genotype ranking in ascending order for the MGIDI index. The selected genotypes based on this index are shown in red. The central red circle represents the cutpoint according to the selection pressure. (B) The strengths and weaknesses view of the selected genotypes is shown as the proportion of each factor on the computed MGIDI index. The smallest the proportion explained by a factor (closer to the external edge), the closer the traits within that factor are to the ideotype. The dashed line indicates the theoretical value if all the factors had contributed equally. 


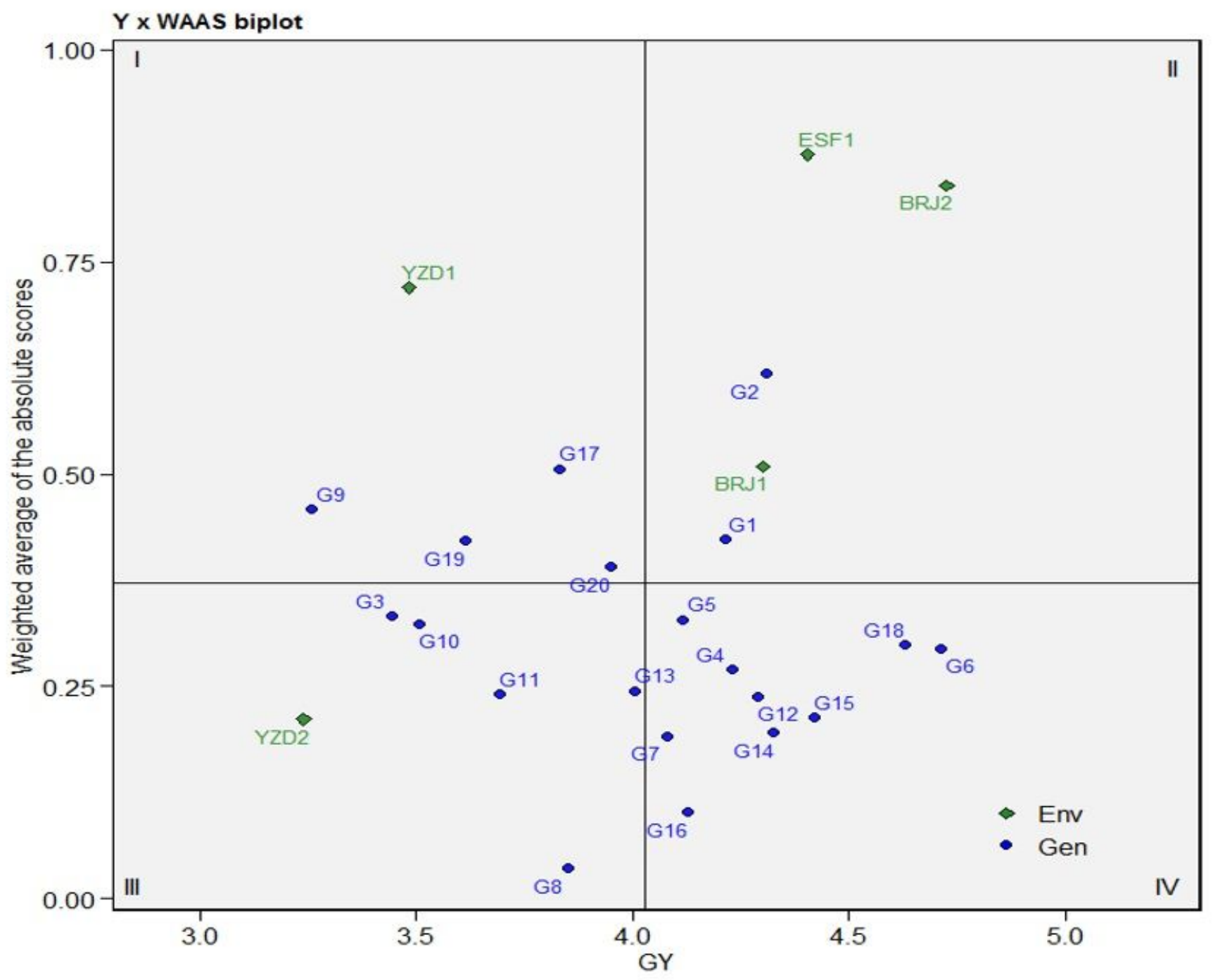

Figure 4

The WAASB $\times$ grain yield (GY) biplot for 20 barley genotypes in five environments. YZD1, Yazd location (2018-2019); YZD2, Yazd location (2019-2020); BRJ1, Birjand location (2018-2019); BRJ2, Birjand location (2019-2020); ESF1, Esfahan location (2018-2019).

\section{Supplementary Files}

This is a list of supplementary files associated with this preprint. Click to download.

- SupplementaryTableS1.pdf 